\title{
COMBINED ACTION OF ADSORPTION AND CATALYTIC OXIDATION IN ALUMINUM DYE REMOVAL BY GROUNDWATER TREATMENT WASTE
}

\author{
Edita SODAITIENĖ, Danutė KAUŠPĖDIENĖ, Audronė GEFENIENE* \\ Romas RAGAUSKAS, Rimantas RAMANAUSKAS
}

Center for Physical Sciences and Technology, Sauletekio al. 3, LT-10257 Vilnius, Lithuania

Received 22 April 2021; accepted 17 August 2021

\footnotetext{
Highlights

The groundwater treatment sludge (GWTW) is an effective, cheap, and environmentally friendly Fenton-like heterogeneous catalyst.

$\checkmark$ GWTW promotes the degradation of an anodized aluminum dye.

The solution decoloration rate increased with the decrease in $\mathrm{pH}$ and increase in temperature.
}

\begin{abstract}
The performance of groundwater treatment waste (GWTW) as an adsorbent and catalyst in the decoloration of aluminum dye Sanodure green LWN (SG) solution was investigated. The raw GWTW was more suitable for dye removal than calcined at $800{ }^{\circ} \mathrm{C}$ temperature. The catalytic activity of GWTW in Fenton-like reactions in sunlight increases with decreasing $\mathrm{pH}$ from 5.5 to 2.5 and increasing temperature from 20 to $60^{\circ} \mathrm{C}$. The rate of $70 \%$ decoloration in the first $5 \mathrm{~min}$ and $92 \%$ after $50 \mathrm{~min}$ of $100 \mathrm{mg} / \mathrm{L} \mathrm{SG}$ dye solution was reached at $50{ }^{\circ} \mathrm{C}$ and $\mathrm{pH} 3$. Kinetics of the SG dye color removal fitted well with the double exponential and two-stage pseudo-first-order kinetic models. The activation energy of the first stage of the SG dye degradation reaction is $30.45 \mathrm{~kJ} / \mathrm{mol}$. GWTW could be re-used for the pre-treatment of dye-contaminated wastewater before entering the wastewater treatment plant.
\end{abstract}

Keywords: waste management technologies, groundwater treatment waste, adsorption, heterogeneous catalysis, dye removal.

\section{Introduction}

From ancient times, the people desired to look at colorful, beautiful-looking products in their environment and used them extensively in daily life. Unfortunately, the chemical compounds that give the color can be harmful to the environment and dangerous for humans (Mittal, 2020). It is well known that large quantities of organic dyes are consumed in the textile industry. However, metal coloring is also performed both for technical and decorative purposes. Surfaces of aluminum alloys are usually protected by forming anodic films that can be colored (Chang et al., 2016). The color range of anodized aluminum depends not only on the aluminum alloy base but also on the dye composition. Mono-azo, poly-azo, and metal complex organic dyes are widely used for aluminum coloring. Therefore, they fall into the wastewater. Metal complex dyes contain not only complex aromatic ligands but also heavy metals, which increase their toxicity (Sanodure Green
Safety datasheet, 2020; Hou et al., 2016). Such wastewater needs to be purified, so that clean water is returned to production.

Although colored anodized aluminum is often used in various decorative products, nowadays, wastewater contaminated with dyes is usually treated according to the dye removal technology traditionally applied in the textile industry. However, metals and textiles are dyed differently, which is one of the factors determining the wastewater treatment processes (Chang et al., 2016; Banazadeh et al., 2016).

Adsorption has become one of the most frequently used technologies for the removal of dyes. Polymeric biocomposites (Noreen et al., 2020), biomass and its magnetic composites (Jabeen \& Bhatti, 2021), chitosan-based adsorbents (Kausar et al., 2021) have been tested for dye adsorption. Waste materials and products of their modification were also utilized as adsorbents to remove organic

${ }^{\star}$ Corresponding author. E-mail: audrone.gefeniene@ftmc.lt 
dyes (Mittal \& Mittal, 2015); Haddad et al., 2021). Efficient removal of various dyes (Malachite Green, Crystal Violet, Rhodamine B, Methylene Blue, Chrysoidine R, and Congo Red) was attained using carbon-based materials as adsorbents: activated carbon (Arora et al., 2020; Patel et al., 2021), metal-organic framework (Soni et al., 2020), carbon nanofibers (Saharan et al., 2021), ordered mesoporous carbon (Mariyam et al., 2021a, 2021b) and activated carbon nanocomposite (Gupta et al., 2020). A novel surface imprinted resin with selective adsorption capability and the dye recognition ability was synthesized and showed excellent adsorption performance (Sun et al., 2021). An innovative adsorbent coating technology for industrial wastewater treatment is extensively studied (Azha et al., 2021).

The advanced oxidation processes (AOPs) are widely applied for the decomposition of various organic contaminants (Bhat \& Gogate, 2021; Banazadeh et al., 2016; Horáková et al., 2014; Oller et al., 2011). Using AOPs and nanostructured metals or metal oxides as catalysts, the hydroxyl radicals $(\cdot \mathrm{OH})$ from $\mathrm{H}_{2} \mathrm{O}_{2}$ are generated, which break down organic pollutants into $\mathrm{CO}_{2}, \mathrm{H}_{2} \mathrm{O}$, and small organic molecules (Neyens \& Baeyens, 2003). The elements of varying oxidation states such as iron, manganese, copper, chromium, cobalt, cerium, and ruthenium can activate hydrogen peroxide $\left(\mathrm{H}_{2} \mathrm{O}_{2}\right)$ in both homogeneous and heterogeneous reactions under neutral or alkaline conditions (Bokare \& Choi, 2014).

Iron-based nanoparticles of various types are materials of interest in the role of catalysts or adsorbents in water and wastewater treatment (Aragaw et al., 2021).

Iron oxides, hydroxides, and oxyhydroxides are classified as promising heterogeneous Fenton catalysts (Thomas et al., 2021; Garrido-Ramírez et al., 2010). Natural iron minerals and synthetic iron materials are widely used to treat organic contaminants (Luo et al., 2021). The main positive features are their abundance, negligible toxicity, low cost, and high catalytic activity (Thomas et al., 2021). The advantage of heterogeneous catalysts is that they are active in acidic and near-neutral media (Moradi et al., 2020). The catalytic efficiency of heterogeneous Fenton catalysts depends on their physical and chemical properties, structural and surface characteristics (Domacena et al., 2020; Garrido-Ramírez et al., 2010). In a heterogeneous Fenton system, the reduction of $\mathrm{Fe}(\mathrm{III})$ to $\mathrm{Fe}(\mathrm{II})$ by $\mathrm{H}_{2} \mathrm{O}_{2}$ is the degradation speed limiting step (Lai et al., 2021). Heterogeneous Fenton reactions can be accelerated using novel strategies: promoting $\mathrm{H}_{2} \mathrm{O}_{2}$ decomposition, controlling catalyst morphology, or introducing electronrich materials (Zhu et al., 2019). The efficiency of the heterogeneous Fenton process was improved by using the nanomaterial composed of ferric oxide, silica, and alumina (Nguyen et al., 2021). Degradation of Synozol Red reactive dye was achieved using $\mathrm{ZnFe}_{2} \mathrm{O}_{4}$ catalyst and the composite prepared from $\mathrm{ZnFe}_{2} \mathrm{O}_{4}$ and graphene oxide (Nadeem et al., 2020). Nanocomposites of goethite and akaganeite demonstrated photocatalytic activity by removing the color of Methyl Orange (Pal et al., 2020). Iron compounds can be supported on other solid materials (Thomas et al., 2021; Garrido-Ramírez et al., 2010). Iron-containing catalysts loaded on activated carbon (Rubeena et al., 2018) or silica (Perrotti et al., 2019) enhanced the dye degradation.

Very often, homogeneous and heterogeneous Fenton reactions occur simultaneously, especially in acidic mediums. The iron leached from the solid surface may initiate a homogeneous process (Thomas et al., 2021), and therefore, various iron-rich materials demonstrate stronger catalytic activity (Li et al., 2020). The contribution of heterogeneous and homogeneous processes was studied by Prucek and coworkers (Prucek et al., 2009). The role of homogeneous reaction in the generation of $\bullet \mathrm{OH}$ radicals was considered using $\alpha-\mathrm{FeOOH}$ as a catalyst (Miao et al., 2018).

The synergistic effect of adsorption and the Fenton process using bifunctional materials is widely explored (Bello \& Raman, 2019). Adsorption and catalysis using activated carbons and $\mathrm{H}_{2} \mathrm{O}_{2}$ were combined for the decoloration of dye solutions (Santos et al., 2009). The impact of adsorption and catalytic activation on removing of Methyl Orange dye by iron oxyhydroxides supported on aminofunctionalized silica was determined (Perrotti et al., 2019).

Recently, the catalytic activity of wastes of various compositions generated during industrial processes has been tested. These iron-rich solids may be suitable for activating hydrogen peroxide. Using steel-making or goldmine waste as catalysts instead of iron salts can reduce the cost of treating wastewater contaminated with methyl orange and other dyes without compromising process efficiency (Ali et al., 2013; Montoya-Bautista et al., 2019; Huang et al., 2011). FeO-containing iron slag wastes were employed to degrade Reactive Red 24 dye in an aqueous solution (Van et al., 2019). Amorphous FeOOH was prepared from fly ash and used as a heterogeneous photo-Fenton catalyst ( $\mathrm{Li}$ \& Zhang, 2010). The deposits formed on the internal surfaces of pipes from the drinking water network usually are rich in various forms of iron oxyhydroxides. The possibility of catalytic degradation of the pesticide paraquat with hydrogen peroxide and the real pipe deposits as catalysts was studied (Oliveira et al., 2012). Ferric waste sludge produced during the purification of water was employed for the catalytic oxidation of volatile organic compounds (VOCs) with $\mathrm{H}_{2} \mathrm{O}_{2}$ (Sanchis et al., 2019).

In this study, the groundwater treatment waste (GWTW) and $\mathrm{H}_{2} \mathrm{O}_{2}$ were used as environmentally friendly materials in the roles of an adsorbent/catalyst and an oxidant, respectively. We explored sunlight as a cheap and sustainable source of energy.

The groundwater treatment waste (GWTW) is formed by removing iron and manganese from groundwater by aeration (Zubryte et al., 2020). Nowadays, the reuse of drinking water treatment sludge has become an increasingly important issue (Babatunde \& Zhao, 2007). Therefore, GWTW is extensively studied as a suitable adsorbent for nickel, cadmium, and $\mathrm{CO}_{2}$ (Wołowiec et al., 2019; Ong et al., 2017; Siswoyo et al., 2014; Novoselova, 2013) and as a coagulant to remove natural organics from river water (Albrektienè et al., 2019). 
Since $\mathrm{Fe}_{2} \mathrm{O}_{3}$ predominates in the groundwater treatment waste (GWTW), it could be a cheap and easily accessible adsorbent/Fenton-like catalyst for the removal of dyes. In the literature, we have not yet been able to find the results of such studies. Therefore, the purpose of our work was to assess the performance of GWTW as natural bifunctional material in the decoloration of the anodized aluminum dye Sanodure Green LWN (SG) solution. The choice of low-cost, efficient, and environmentally friendly catalysts is particularly relevant for small businesses involved in the small-scale production of colored aluminum parts. The synergetic effect of GWTW and $\mathrm{H}_{2} \mathrm{O}_{2}$ in the adsorption and oxidation of the dye was evaluated under different solution $\mathrm{pH}$ and temperature conditions. The SG dye removal experiments in the absence of $\mathrm{H}_{2} \mathrm{O}_{2}$ or GWTW were also carried out to assess the advantage of the combined process of adsorption and catalytic oxidation.

\section{Materials and methods}

Groundwater treatment waste (GWTW) was obtained from the Antaviliai drinking water supply station in Vilnius, Lithuania. Raw GWTW was air-dried in the laboratory at room temperature for 4 weeks. After that, it was finely crushed in a pestle and stored in a desiccator. Before Xray diffraction analysis and the experiments with calcined GWTW, the samples were preheated at $800^{\circ} \mathrm{C}$ in a muffle furnace for $5 \mathrm{~h}$ in an air atmosphere.

Commercial adsorbents, including activated carbon NORIT PK 1-3 (Cabot Norit), macroporous resins (weak base Macronet MN 150, non-ionic Macronet MN 200, strong acid Macronet MN 500 (Purolite Company)), and mixed bed resin PMB 101 (Pure Resin Co., Ltd) were used to compare their adsorption capacity for SG dye.

The Sanodure Green LWN (SG) dye for anodized aluminum was obtained from Clariant International Ltd. Switzerland. It belongs to the azo dyestuff/chromium complex anionic dye family (Figure 1).

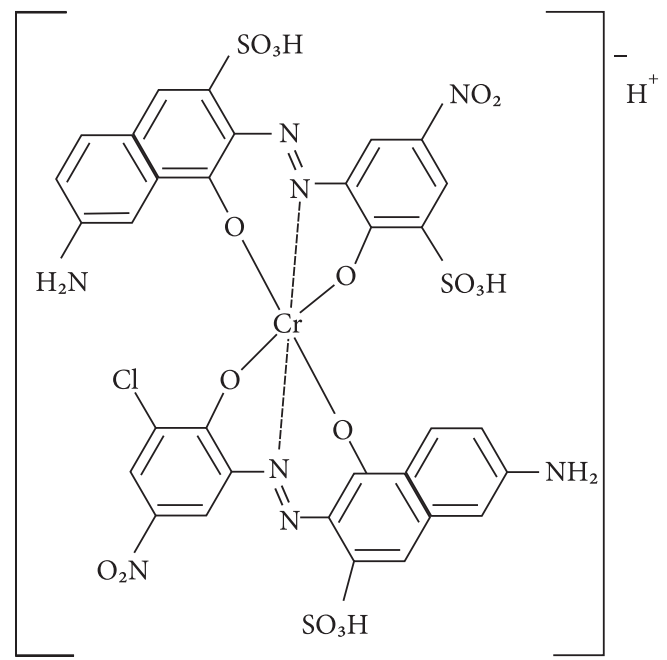

Figure 1. Structure of the chromium complex anionic dye suitable for anodized aluminum dyeing (Heber, 2015)
A scanning electron microscope EVO 50EP (Carl Zeiss SMT AG) with a secondary electron detector (low vacuum mode, $10 \mathrm{kV}, 50 \mathrm{~Pa}$, working distance $10 \mathrm{~mm}$ ) was used to investigate of GWTW surface morphology.

FTIR spectra of GWTW and SG dye were recorded from 100 scans in the range of $650-4000 \mathrm{~cm}^{-1}$ by spectrometer ALPHA (Bruker, Germany).

$\mathrm{X}$-ray powder diffraction (XRD) data for the preheated GWTW were obtained with an X-ray diffractometer SmartLab (Rigaku, Japan), equipped with a $9 \mathrm{~kW}$ rotating $\mathrm{Cu}$ anode X-ray tube. The measurements were done in the range $2 \theta=15-60^{\circ}$. Phases of GWTW were identified using the software package PDXL (Rigaku) and ICDD powder diffraction database PDF-4+ (2013). X-ray fluorescence spectrometer AxiosmAX (PANalytical, Netherlands) with wave dispersion (XRF-WD) and $4 \mathrm{~kW} \mathrm{Rh}$ anode was used to ascertain the elemental composition of dry GWTW specimens. For testing, the samples were primed up to micron particle size (rotary mill $550 \mathrm{rpm}$ for $5 \mathrm{~min}$ ), and $37 \mathrm{~mm}$ diameter tablets were compressed by a hydraulic press at $150 \mathrm{KN} \mathrm{cm}^{-2}$. Omnian (PANalytical) software was applied for the quantification of elements in the standardless analysis. Chemical composition was adjusted using benchmarks ESK, IMZ-267, PI 3.13, NCSDC18013, and NCSD60105. XPS analysis was performed using ESCALAB MKII spectrometer fitted with an XR4 twin anode.

The combined adsorption and catalytic degradation experiments were conducted as follows: into a $10 \mathrm{~mL}$ of aqueous SG dye solution $(100 \mathrm{mg} / \mathrm{L})$ at a temperature of $20^{\circ} \mathrm{C}, 50{ }^{\circ} \mathrm{C}$, or $60^{\circ} \mathrm{C} 5 \mathrm{mg}$ of GWTW was poured. After that $\mathrm{pH}$ of the system was adjusted with $5 \mathrm{M} \mathrm{HCl}$, and the pre-determined optimal amount of $1 \mathrm{~mL}$ of hydrogen peroxide $\mathrm{H}_{2} \mathrm{O}_{2}$ (35 wt.\%) was immediately added. During the reaction time, the mixture was constantly stirred. The solution color faded when the reaction proceeded. After some scheduled time, $5 \mathrm{ml}$ of centrifuged supernatant was carefully transferred into a quartz cuvette for UV-visible spectral measurement. After that, the solution and sludge were transferred back to the adsorption/catalytic reaction vessel. The procedure was repeated to follow the dye removal progress, and UV-visible spectra were recorded at the pre-determined time. For comparison, at the same conditions, adsorption tests were performed with GWTW and without $\mathrm{H}_{2} \mathrm{O}_{2}$ or non-catalytic oxidation with $\mathrm{H}_{2} \mathrm{O}_{2}$ and without a solid phase. A series of catalytic experiments were also conducted with an introductory adsorption step during which the flasks with SG dye solutions and GWTW were stirred for $30 \mathrm{~min}$ in the dark without the addition of $\mathrm{H}_{2} \mathrm{O}_{2}$ (Xiao et al., 2018).

The degradation rate of the SG dye (color removal efficiency, RE) was assessed by measuring UV-visible spectra with a Varian Cary 50 spectrometer (Agilent Technologies, USA). Based on the UV-vis absorbance data at the wavelength of $630 \mathrm{~nm}$, the removal efficiency was calculated according to Eq. (1):

$$
\text { Removal efficiency, } \%=\frac{\left(A_{0}-A_{t}\right)}{A_{0}} \times 100 \%,
$$


where $A_{0}$ is the dye solution absorbance at $t=0 ; A_{t}$ is the absorbance at a time $t$.

The sorption capacity of the GWTW $q(\mathrm{mg} / \mathrm{g})$ was calculated according to Eq. (2):

$$
q, \mathrm{mg} / \mathrm{g}=\frac{\left(C_{0}-C_{t}\right) \times V}{m},
$$

where $C_{0}$ and $C_{t}$ are the concentrations $(\mathrm{mg} / \mathrm{L})$ of the SG dye in the solution before and after sorption determined from the calibration curve $A=f(C)$, respectively. $V$ is the volume of the dye solution $(\mathrm{L})$, and $m$ is the dry GWTW (g) mass.

\section{Results and discussion}

\subsection{Characterization of the GWTW}

The scanning electron microscopy image of the raw GWTW dried at room temperature is shown in Figure 2a. It shows that the powder consists of 50-200 nm spherical particles adhering to each other into agglomerates.

Groundwater supplied to Lithuanian consumers is of calcium-magnesium-bicarbonate type (Diliūnas et al., 2006). X-ray diffraction analysis of raw GWTW has shown that this material at room temperature was of amorphous character. The chemical composition and physical properties of iron(III) hydroxide differ from the initial state before heating (Kan et al., 2016). From the X-ray diffractogram presented in Figure $2 \mathrm{~b}$, we can conclude a crystalline cubic phase of maghemite $\left(\gamma-\mathrm{Fe}_{2} \mathrm{O}_{3}\right.$; ICDD 00-039-1346) and hexagonal phase of $\mathrm{SiO}_{2}$ (ICCD 00-046-1045) was formed after the heating of a GWTW sample at $800{ }^{\circ} \mathrm{C}$ in an air atmosphere. The presence of $\mathrm{SiO}_{2}$ in GWTW is a result of a groundwater flow through a sand filter. The Xray fluorescence spectroscopy confirmed that the GWTW is eco-friendly material rich in iron compounds. In the air-dried sediment, the percentage of iron and oxygen was $43.5 \mathrm{wt} \%$ and $44.9 \mathrm{wt} \%$, respectively. The composition of GWTW expressed in the form of oxides is as follows: $77.99 \% \mathrm{Fe}_{2} \mathrm{O}_{3}, 5.23 \% \mathrm{SiO}_{2}, 7.37 \% \mathrm{CaO}, 7.42 \% \mathrm{P}_{2} \mathrm{O}_{5}, 0.48 \%$ $\mathrm{MnO}, 0.57 \% \mathrm{SO}_{3}$, and $0.32 \% \mathrm{MgO}$. The data of X-ray

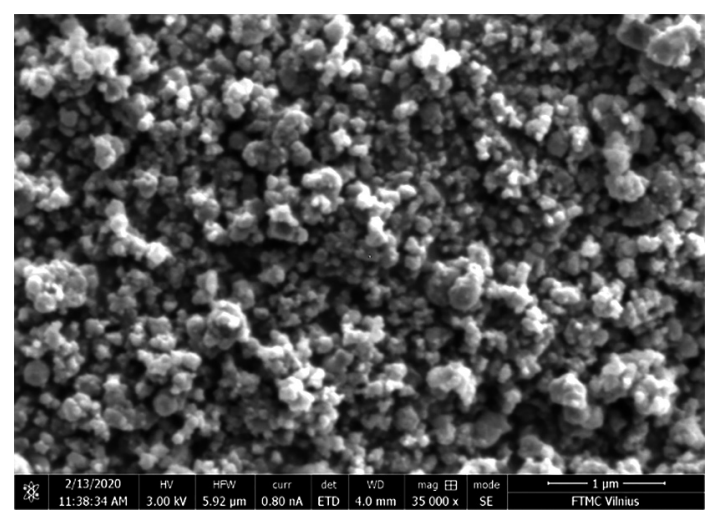

a) fluorescence spectroscopy showed that the content of $\mathrm{Al}$, $\mathrm{Ba}, \mathrm{Sr}, \mathrm{K}, \mathrm{Ti}, \mathrm{As}$, and $\mathrm{Cl}$ do not exceed $0.1 \mathrm{wt} \%$. The detected chemical elements are transferred to GWTW from the groundwater in the form of insoluble compounds together with iron hydroxides and oxides.

The chemical state of $\mathrm{Fe}$ and $\mathrm{O}$ elements in raw GWTW was determined by XPS analysis (Figure 3). In the Fe $2 \mathrm{p}$ spectrum, Fe $2 \mathrm{p}_{1 / 2}$ peak at $725 \mathrm{eV}$ and $\mathrm{Fe} 2 \mathrm{p}_{3 / 2}$ peak at $712.3 \mathrm{eV}$ can be related to the $\mathrm{Fe}-\mathrm{OH}$ binding energy in the hydrous ferric oxides and oxyhydroxides (goethite, lepidocrocite). Meanwhile, the Fe $2 \mathrm{p}_{3 / 2}$ peak at $710.5 \mathrm{eV}$ corresponds to the $\mathrm{Fe}-\mathrm{O}$ binding energy in hematite $\left(\alpha-\mathrm{Fe}_{2} \mathrm{O}_{3}\right)$ (McIntyre \& Zetaruk, 1977; Grosvenor et al., 2004). In the $\mathrm{O} 1 \mathrm{~s}$ spectrum, peaks at $529.5 \mathrm{eV}, 530.54 \mathrm{eV}$, $531.6 \mathrm{eV}$ correspond to oxygen binding with $\mathrm{Fe}(\mathrm{Fe}-\mathrm{O})$ and hydroxyl binding with $\mathrm{Fe}(\mathrm{Fe}-\mathrm{OH})$. The peak at $532.9 \mathrm{eV}$ can be assigned to molecular water (McIntyre \& Zetaruk, 1977; Grosvenor et al., 2004; Leiviskä et al., 2019). As the major components of GWTW are hydrous ferric oxides $\left(\mathrm{Fe}_{2} \mathrm{O}_{3} \cdot \mathrm{nH}_{2} \mathrm{O}\right)$, iron oxyhydroxides $(\mathrm{FeOOH})$, and oxides $\left(\mathrm{Fe}_{2} \mathrm{O}_{3}\right)$, it can activate the decomposition of hydrogen peroxide to its radicals.

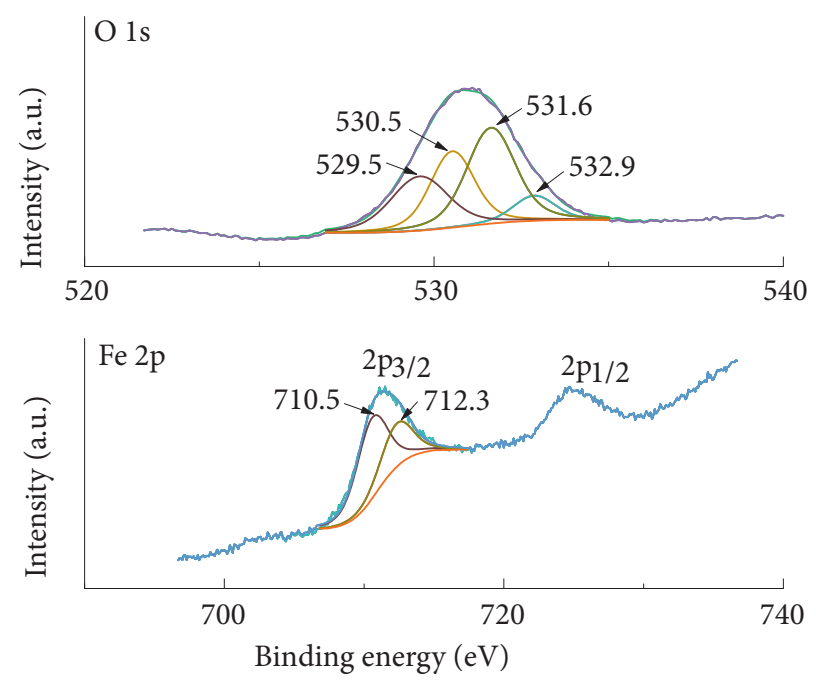

Figure 3. The high-resolution XPS spectra of $\mathrm{O} 1 \mathrm{~s}$ and $\mathrm{Fe} 2 \mathrm{p}$ of raw GWTW

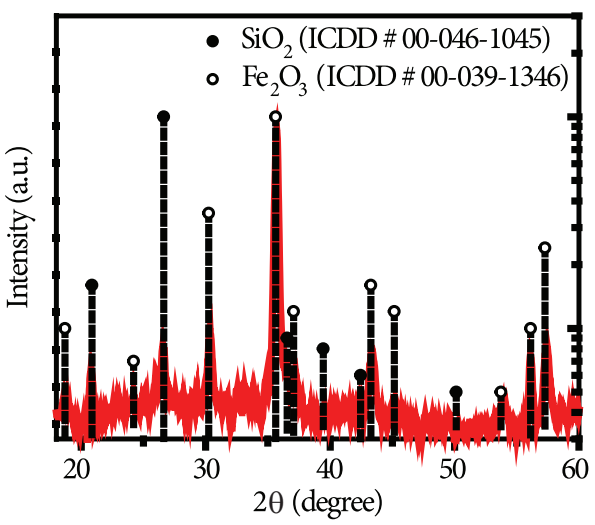

b)

Figure 2. SEM image of the raw GWTW dried at room temperature (a) and XRD spectrum of the GWTW surface after $5 \mathrm{~h}$ heating at $800{ }^{\circ} \mathrm{C}$ in an air atmosphere (b) 
The adsorption capacity and catalytic activity are strongly related to the specific surface area of iron-oxide minerals (Garrido-Ramírez et al., 2010). The BET-specific surface area of raw GWTW dried at room temperature and used in this work for the SG dye adsorption and destruction was $34.76 \mathrm{~m}^{2} \mathrm{~g}^{-1}$ (Sodaitienè et al., 2021).

FTIR analysis of GWTW and SG dye was carried out to identify the functional groups and chemical bonds. The FTIR spectra are presented in Figure 4.

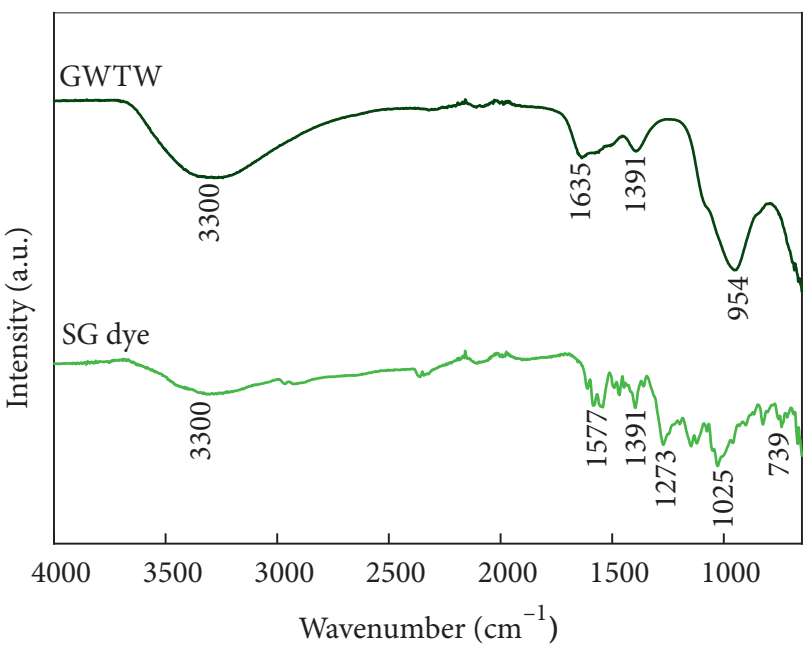

Figure 4. FTIR spectra of metal-complex SG dye and groundwater treatment waste

FTIR spectrum of SG dye shows peaks characteristic to azo dyes (Prati et al., 2016). The peaks located at $1472 \mathrm{~cm}^{-1}$ can be ascribed to azo bond $(\mathrm{N}=\mathrm{N})$ vibrations (Prati et al., 2016). The peaks between 1000 and 1200 correspond to the $\mathrm{SO}_{3}$ group: symmetric stretching vibrations of $\mathrm{S}=\mathrm{O}$ bonds at $1025 \mathrm{~cm}^{-1}$ and $1121 \mathrm{~cm}^{-1}$ (Sun et al., 2021) and asymmetric vibrations at $1147 \mathrm{~cm}^{-1}$. The peaks in the region of $1391 \mathrm{~cm}^{-1}$ can be attributed to the symmetrical and asymmetrical bending vibrations of the $\mathrm{CH}_{3}$ functional groups (Bartošová et al., 2017). The peak located at $1273 \mathrm{~cm}^{-1}$ can be ascribed to the $\mathrm{C}-\mathrm{N}$ aromatic stretching vibrations (Katsoukis et al., 2019). The peaks observed at $1541 \mathrm{~cm}^{-1}, 1577 \mathrm{~cm}^{-1}$, and $1610 \mathrm{~cm}^{-1}$ are assigned to the aromatic $\mathrm{C}=\mathrm{C}$ vibrations of the dye (Prati et al., 2016). The spectrum exhibits the out-of-plane $\mathrm{C}-\mathrm{H}$ bending vibrations of aromatic rings at $825 \mathrm{~cm}^{-1}$ and $739 \mathrm{~cm}^{-1}$ (Paredes-Laverde et al., 2021). The broad band in the region of $3000-3600 \mathrm{~cm}^{-1}$ can be attributed to the stretching vibrations of O-H and N-H (Prati et al., 2016).

The broad band at $3000-3600 \mathrm{~cm}^{-1}$ is characteristic of the stretching vibrations of $\mathrm{O}-\mathrm{H}$ bonds in adsorbed water molecules. The peak located at $1635 \mathrm{~cm}^{-1}$ corresponds to the bending vibration of $\mathrm{O}-\mathrm{H}$ of adsorbed water (Tang et al., 2019). The peak at $1391 \mathrm{~cm}^{-1}$ shows the $\mathrm{C}-\mathrm{O}$ bonds in the adsorbed carbonates (Ociński et al., 2016). Bending vibration of $\mathrm{Fe}-\mathrm{O}$ bonds is observed at $954 \mathrm{~cm}^{-1}$. A band in the region of $670 \mathrm{~cm}^{-1}$ comes from the $\mathrm{Fe}-\mathrm{O}$ stretching vibration (Zhang et al., 2017).

\subsection{Decoloration of SG dye solutions using three different approaches}

The SG dye removal experiments have been carried out using three different approaches to elucidate the catalytic activity of GWTW in a Fenton-like reaction. The solution decoloration efficiency using the catalytic degradation approach was evaluated for the systems containing GWTW as a potential catalyst and hydrogen peroxide as an oxidant. For comparison, a simple adsorption process without the presence of $\mathrm{H}_{2} \mathrm{O}_{2}$ was applied for the removal of color under the same experimental conditions ( $\mathrm{pH}$, temperature, solution volume to GWTW mass ratio). The analogous control tests were also performed to ascertain the ability of $\mathrm{H}_{2} \mathrm{O}_{2}$ alone to degrade the SG dye molecules. The process of SG dye solution decoloration was monitored by UV-visible spectral measurements (Figure 5). The pathway of SG dye oxidation with $\mathrm{H}_{2} \mathrm{O}_{2}$ in the presence of GWTW can be considered by examining the UV-vis spectra presented in Figure 5a. The immediate
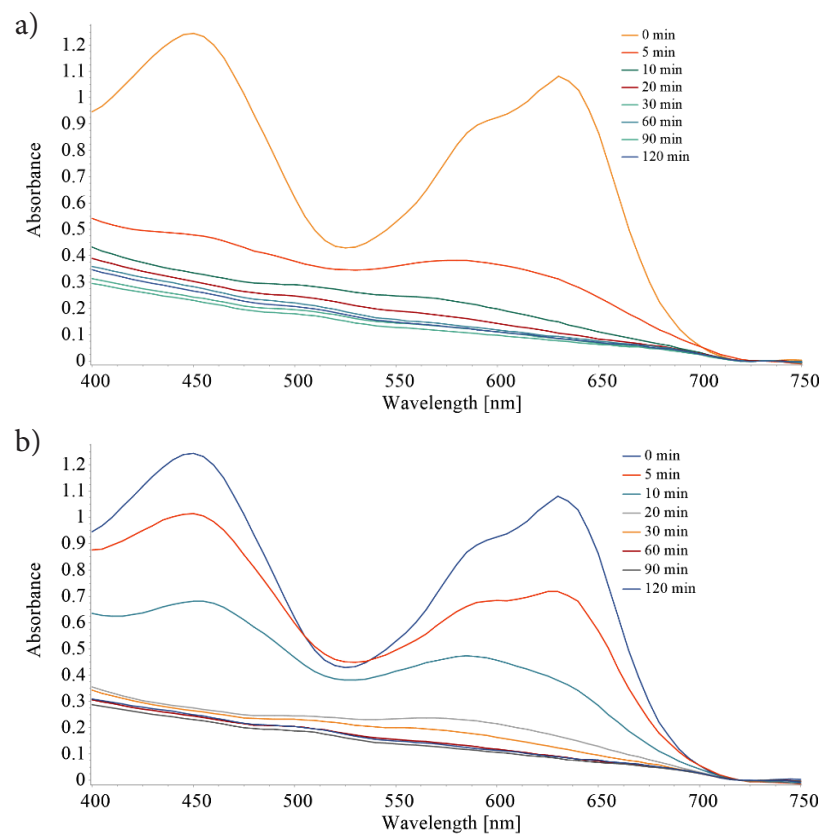

c)

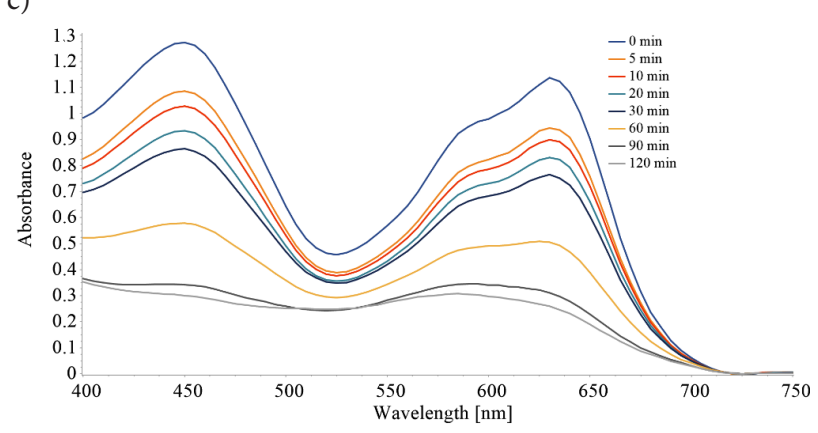

Figure 5. Time-dependent absorption spectra of the SG dye solution before and during: (a) degradation reaction with $\mathrm{H}_{2} \mathrm{O}_{2}$ and GWTW catalyst; (b) adsorption on GWTW in the absence of $\mathrm{H}_{2} \mathrm{O}_{2}$; (c) non-catalytic degradation with $\mathrm{H}_{2} \mathrm{O}_{2}$ in the absence of GWTW. Conditions: concentration of SG dye $100 \mathrm{mg} / \mathrm{L}$, volume of dye solution $10 \mathrm{~mL}, 5 \mathrm{mg}$ GWTW, $1 \mathrm{~mL} \mathrm{H}_{2} \mathrm{O}_{2}, \mathrm{pH} 3, \mathrm{~T}=50^{\circ} \mathrm{C}$ 
fast decoloration of SG dye solution was observed at the beginning of the catalytic reaction.

More than $70 \%$ decoloration was achieved during the first $5 \mathrm{~min}$, and the main peaks disappeared after $10 \mathrm{~min}$ of the reaction. In comparison, $32 \%$ and $63 \%$ decoloration was attained in the SG dye adsorption process after the same periods of time (Figure $5 \mathrm{~b}$ ). In the case of non-catalytic peroxidation of the SG dye molecules, both characteristic peaks gradually decreased over the reaction time during the degradation reaction (Figure 5c). By comparing the spectra presented in Figure $5 \mathrm{a}-\mathrm{c}$, it is clear that the addition of $\mathrm{H}_{2} \mathrm{O}_{2}$ to the system containing GWTW improved the SG dye removal process. The combination of GWTW as adsorbent and heterogeneous catalyst with $\mathrm{H}_{2} \mathrm{O}_{2}$ as oxidant reveals the synergistic effect and the increased potential of the used solid amorphous material in the removal of SG dye. As can be observed from Figure $5 c$, the peroxidation without the presence of GWTW was the least effective, and the absorbance of the SG dye solution decreased slowly and gradually. In this case, the color intensity of the SG dye solution was lost because of the direct attack of $\mathrm{H}_{2} \mathrm{O}_{2}$ on SG dye molecules (Santos et al., 2009).

As we can see from the photograph in Figure 6, the visual appearance of GWTW during the Fenton-like catalytic degradation of the dye differs from that in the case of the SG dye adsorption without the addition of the $\mathrm{H}_{2} \mathrm{O}_{2}$ oxidant. When the catalytic degradation proceeds, the GWTW particles regain their original color. In contrast, the GWTW surface acquires the dark green color after the coverage with SG dye molecules during the adsorption process. It is evident that the removal of the SG dye using the catalytic oxidation approach leads to the destruction of the dye molecule structure. Our future investigations aim is to determine the COD and TOC parameters for the SG dye solution before and after the treatment with GWTW and $\mathrm{H}_{2} \mathrm{O}_{2}$. It is essential to ascertain the ability of GWTW to adsorb the dye degradation products, including chromium. As it was mentioned earlier, the specific surface area of the GWTW measured by the BET method was relatively large, up to $35 \mathrm{~m}^{2} \mathrm{~g}^{-1}$. The value of this parameter

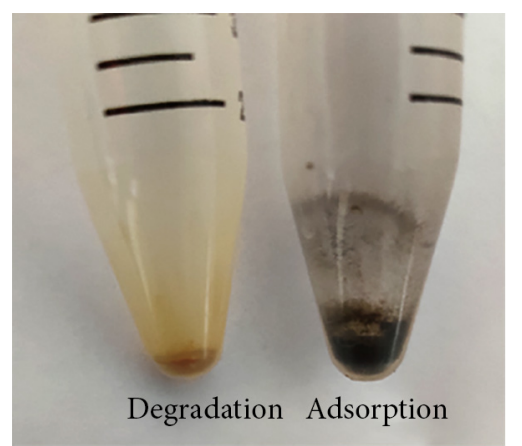

Figure 6. A photograph of the GWTW: (in the left) in the case of the catalytic degradation of SG dye with $\mathrm{H}_{2} \mathrm{O}_{2}$; (in the right) in the case of the adsorption of SG dye without $\mathrm{H}_{2} \mathrm{O}_{2}$ significantly affects the pollutant removal efficiency by applying adsorption as a single independent method. However, the BET surface area of the material also determines its catalytic performance because the degradation process is related to the adsorption of pollutants and oxidizing agents on the surface of the catalyst. A higher number of active centers can be expected in a larger specific surface area of heterogenous catalyst (Zheng et al., 2015).

The improved action of GWTW in the presence of $\mathrm{H}_{2} \mathrm{O}_{2}$ can be seen from the kinetic curves of SG dye removal (Figure 7). It is obvious that the higher color removal rate may be achieved by the combined process of adsorption and catalytic degradation rather than by adsorption alone. By comparing the curves presented in Figure 7, we can see that the addition of $\mathrm{H}_{2} \mathrm{O}_{2}$ to the system containing GWTW accelerated the SG dye removal process. The processes of combined adsorption/ Fenton-like oxidation (degradation), adsorption alone, and non-catalytic oxidation with $\mathrm{H}_{2} \mathrm{O}_{2}$ (peroxidation) were modeled by a double exponential model (Guz et al., 2014). Experimental data for the three different systems were fitted with a double exponential equation:

$$
\frac{C}{C_{0}}=a \times e^{-k_{1} t}+b \times e^{-k_{2} t}
$$

where $C$ is the SG dye concentration at time $t, C_{0}$ - initial concentration; $k_{1}$ and $k_{2}$ - reaction rate constants.

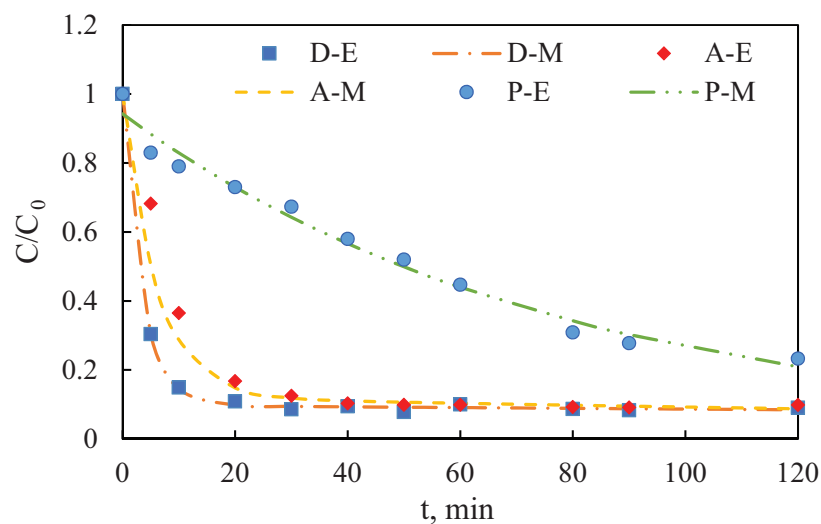

Figure 7. Experimental (E) kinetic data (symbols) and double exponential model (M) fits (lines) for the SG dye removal in different systems: $\mathrm{SG}+\mathrm{GWTW}+\mathrm{H}_{2} \mathrm{O}_{2}$ (Degradation (D)), $\mathrm{SG}+\mathrm{GWTW}$ (Adsorption (A)), $\mathrm{SG}+\mathrm{H}_{2} \mathrm{O}_{2}$ (Peroxidation (P)). Conditions: concentration of SG dye $100 \mathrm{mg} / \mathrm{L}$, volume of dye solution $10 \mathrm{~mL}, 5 \mathrm{mg} \mathrm{GWTW}, 1 \mathrm{~mL} \mathrm{H}_{2} \mathrm{O}_{2}, \mathrm{pH} \mathrm{3,} \mathrm{T}=50^{\circ} \mathrm{C}$

As we can see from Figure 7, the experimental data fit well in the double exponential model with the $\mathrm{R}^{2}$ values $>0.98$. Correlation coefficients and the kinetic parameters data are presented in Table 1. The dye removal rate constants listed in Table 1 showed that $k_{1}>k_{2}$ for all the examined processes except for homogeneous peroxidation at $20^{\circ} \mathrm{C}$. In the case of non-catalytic peroxidation, initial color removal rate constants $k_{1}$ are relatively low, especially at $20^{\circ} \mathrm{C}$ temperature (Table 1 ). 
Table 1. Kinetic parameters based on the double exponential model for the removal of SG dye using degradation, adsorption, and peroxidation approaches

\begin{tabular}{|l|c|c|c|c|c|}
\hline \multicolumn{1}{|c|}{ System } & $\mathrm{R}^{2}$ & $a$ & $k_{1}\left(\mathrm{~min}^{-1}\right)$ & $b$ & $k_{2}\left(\mathrm{~min}^{-1}\right)$ \\
\hline $\begin{array}{l}\mathrm{SG}+\mathrm{GWTW}+\mathrm{H}_{2} \mathrm{O}_{2} \\
\text { Degradation } 20^{\circ} \mathrm{C}\end{array}$ & 0.9958 & 0.7603 & 0.3175 & 0.2384 & 0.0076 \\
\hline $\begin{array}{l}\mathrm{SG}+\mathrm{GWTW} \\
\text { Adsorption } 20^{\circ} \mathrm{C}\end{array}$ & 0.9981 & 0.7209 & 0.2620 & 0.2777 & 0.0066 \\
\hline $\begin{array}{l}\mathrm{SG}+\mathrm{H}_{2} \mathrm{O}_{2} \\
\text { Peroxidation } 20^{\circ} \mathrm{C}\end{array}$ & 0.9980 & 0.8491 & 0.0026 & 0.1507 & 0.3979 \\
\hline $\begin{array}{l}\mathrm{SG}+\mathrm{GWTW}+\mathrm{H}_{2} \mathrm{O}_{2} \\
\text { Degradation } 50^{\circ} \mathrm{C}\end{array}$ & 0.9993 & 0.9020 & 0.2926 & 0.1222 & 0.0012 \\
\hline $\begin{array}{l}\mathrm{SG}+\mathrm{GWTW} \\
\text { Adsorption } 50{ }^{\circ} \mathrm{C}\end{array}$ & 0.9988 & 0.8781 & 0.1650 & 0.1075 & 0.0028 \\
\hline $\begin{array}{l}\mathrm{SG}+\mathrm{H}_{2} \mathrm{O}_{2} \\
\text { Peroxidation } 50{ }^{\circ} \mathrm{C}\end{array}$ & 0.9811 & 0.8351 & 0.0135 & 0.075 \\
\hline
\end{tabular}

\section{3. $\mathrm{pH}$ effect on SG dye degradation efficiency}

The effect of solution $\mathrm{pH}$ on the systems of combined adsorption and heterogeneous catalysis was studied at a $\mathrm{pH}$ range of 2.0-5.5 (acidic and slightly acidic conditions). The importance of solution $\mathrm{pH}$ for the $\mathrm{SG}$ dye removal efficiency can be seen in Figure 8. It shows the results of the SG dye removal study performed involving an initial step called pre-adsorption. During this pre-adsorption period, the color intensity of the SG dye solution decreased due to the interaction of SG dye with GWTW in the dark in the absence of $\mathrm{H}_{2} \mathrm{O}_{2}$. The data presented in Figure 8 show that the SG dye uptake by adsorption in the dark during the first 30 min is highly dependent on the solution $\mathrm{pH}$. The dye removal efficiency (RE) increases from 16.8 to $51 \%$ as the $\mathrm{pH}$ of the solution decreases from 3.3 to 2.0. This is because the adsorption capacity of GWTW changes from $28.9 \mathrm{mg} / \mathrm{g}$ to $95.5 \mathrm{mg} / \mathrm{g}$ after acidification of the solution from $\mathrm{pH} 3.3$ to $\mathrm{pH} 2.0$. When the $\mathrm{pH}$ of the dye solution was not adjusted before the addition of

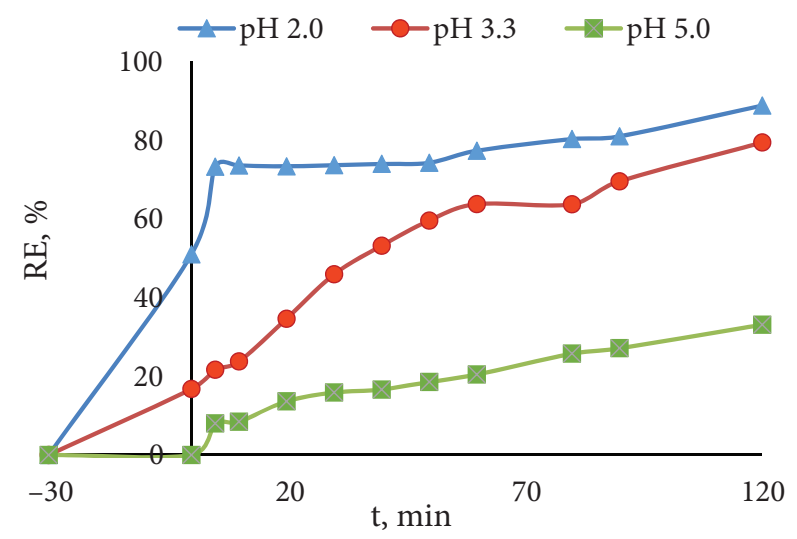

Figure 8. Effect of $\mathrm{pH}$ on the SG dye removal during the twostage process: the first stage $(-30 \mathrm{~min}-0 \mathrm{~min})$ - adsorption in the dark, the second stage ( 0 min-120 min) - combined adsorption/catalytic oxidation. Conditions: SG dye solution concentration $100 \mathrm{mg} / \mathrm{L}$, dye solution volume $10 \mathrm{~mL}, 1 \mathrm{~mL}$ $\mathrm{H}_{2} \mathrm{O}_{2}, 5 \mathrm{mg}$ GWTW catalyst, T $20{ }^{\circ} \mathrm{C}$
$\mathrm{H}_{2} \mathrm{O}_{2}\left(\mathrm{pH}_{0} 5.0\right)$, the adsorption of SG dye molecules was very negligible (Figure 8 ). However, the color fading was initiated when the $\mathrm{H}_{2} \mathrm{O}_{2}$ oxidant entered the adsorption system, and up to $30 \%$ of the dye was removed within $120 \mathrm{~min}$. As we can see from Figure 8, the acidic medium ( $\mathrm{pH} 2.0-3.3$ ) is more favorable for the dye's adsorption and for oxidative dye molecule degradation. In the presence of $\mathrm{H}_{2} \mathrm{O}_{2}$, the rate of decoloration increases with decreasing $\mathrm{pH}$. At $\mathrm{pH} 2.0$, the high removal efficiency of $73 \%$ can be achieved as early as $5 \mathrm{~min}$ after the start of the reaction (Figure 8).

The results of tests of combined adsorption and heterogeneous catalysis carried out without the initial stage of simple adsorption are presented in Figure 9. The dye removal progress demonstrates a similar trend, and the decoloration of the SG dye solution was more efficient in a more acidic medium (Figure 9). The color removal was very fast during the first $5 \mathrm{~min}$ when the solution $\mathrm{pH}$ was in the range of $\mathrm{pH} 2.0-2.5$. Decoloration degree was lower in the system with $\mathrm{pH} 3.7$, but it gradually increased with time. At the same time the

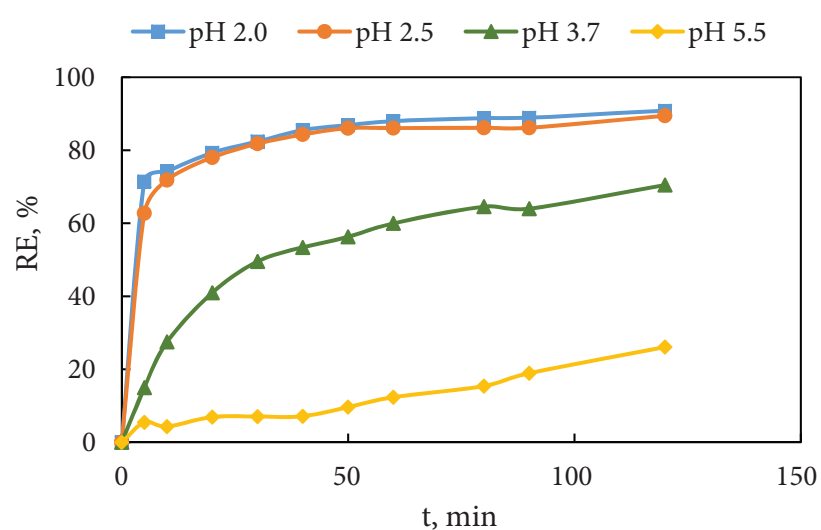

Figure 9. Effect of $\mathrm{pH}$ on the SG dye removal by combined adsorption/catalytic oxidation. Conditions: concentration of SG dye $100 \mathrm{mg} / \mathrm{L}$, the volume of dye solution $10 \mathrm{~mL}, 1 \mathrm{~mL} \mathrm{H}_{2} \mathrm{O}_{2}$, $5 \mathrm{mg}$ GWTW catalyst, T $20^{\circ} \mathrm{C}$ 
dye removal efficiency was rather low in slightly acidic conditions ( $\mathrm{pH} 5-6$ ).

The better performance of the process around $\mathrm{pH}$ $2-3$ could be explained by the chemical properties and composition of the used solid material. The point of zero charge $\left(\mathrm{pH}_{\mathrm{pzc}}\right)$ of GWTW is equal to $\mathrm{pH}=8.0$ (Zubryte et al., 2020), thus under experimental conditions used, the GWTW surface was positively charged (Dzombak \& Morel, 1990). In the acidic medium, the protonation of GWTW increased, which means that the adsorption occurred according to the mechanism of the electrostatic interaction between the positively charged GWTW surface and the dye anion. Additionally, the $\mathrm{pH}$ affects the - OH radical formation rate (Yao et al., 2013; Rubeena et al., 2018). A homogeneous Fenton reaction can also be expected in the acidic medium. As has already been determined in our previous work (Zubryte et al., 2020), the concentration of $\mathrm{Fe}(\mathrm{III})$ in the solution with $\mathrm{pH} 2$ was about $120 \mathrm{mg} / \mathrm{L}$. Similar results were obtained for burgerlike $\mathrm{Fe}_{2} \mathrm{O}_{3}$ (Xiao et al., 2018), where the optimal $\mathrm{pH}$ range for the degradation of Acid Red G dye was determined about 2-3. Homogeneous non-catalytic peroxidation of SG dye was also dependent on solution $\mathrm{pH}$ (data not shown).

\subsection{Effect of dose of the catalyst}

The activity of GWTW catalyst in oxidative degradation of metal complex dye has been investigated depending on the catalyst loading. The rate of the dye degradation increased with increasing catalyst dose from 0.5 to $1.0 \mathrm{~g} / \mathrm{L}$. When the GWTW concentration of $0.5 \mathrm{~g} / \mathrm{L}$ was used, $27.5 \%$ of the SG dye decomposed during the first $10 \mathrm{~min}$, whereas by doubling the amount of catalyst, the degradation efficiency increased up to $62.7 \%$ (Figure 10). After $60 \mathrm{~min}$, about $85 \%$ and $67 \%$ of the dye color was removed with 1.0 and $0.5 \mathrm{~g} / \mathrm{L}$ catalyst loading, respectively. The increased number of active sites on the surface of the GWTW catalyst can explain the enhancement of the SG dye degradation efficiency. The more active centers, the more the $\bullet \mathrm{OH}$ radicals causing the destruction of the SG dye molecules can be formed.

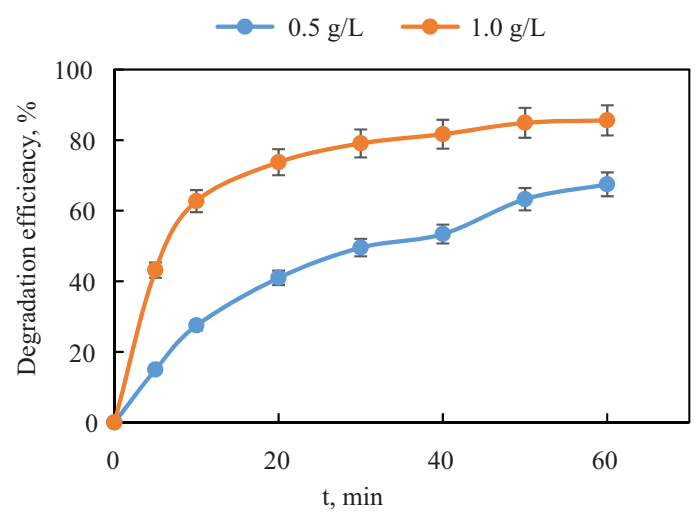

Figure 10. Effect of the catalyst loading on the SG dye degradation efficiency. Conditions: $\mathrm{pH} 3$; $\mathrm{C}_{0}(\mathrm{SG}$ dye $)=100 \mathrm{mg} / \mathrm{L} ; \mathrm{T}=50^{\circ} \mathrm{C}$

\subsection{Effect of temperature on SG dye degradation efficiency}

The effect of temperature on the SG dye solution decoloration was studied in the range of $20-60{ }^{\circ} \mathrm{C}$, solution $\mathrm{pH} 3$, and SG dye concentration $100 \mathrm{mg} / \mathrm{L}$. After $10 \mathrm{~min}$ of reaction, the SG dye removal efficiencies were 27, 67, and $75 \%$ at 20,50 , and $60{ }^{\circ} \mathrm{C}$, respectively. Faster degradation of SG dye with increasing temperature indicates not only increased mobility of the dye molecules but also an increased rate of catalytic reaction. The variation in temperature in the range of $293-323 \mathrm{~K}$ changed the rate of degradation of the SG dye because higher temperatures increased the rate of formation of $\bullet \mathrm{OH}$ radicals in the reaction between $\mathrm{H}_{2} \mathrm{O}_{2}$ and GWTW (Xu et al., 2009; Wilkins, 1974). As we can see from the kinetic curves in Figure 11, the dye decoloration process can be divided into several kinetic regions (Benetoli et al., 2011): the first stage with a high reaction rate from the beginning of the reaction up to $10 \mathrm{~min}$, the middle stage from 10 to $50 \mathrm{~min}$ after which equilibrium is approaching. Analysis of the experimental data of the first and second stages showed that they are in a good fit for the pseudo-first-order kinetics with high $R^{2}$ values $\left(R^{2}=0.84-0.98\right)$. The catalytic degradation of organic dyes very often can be described by pseudo-first-order kinetics (Nasuha et al., 2021; Van et al., 2019).

As a significant excess of $\mathrm{H}_{2} \mathrm{O}_{2}$ was used in the SG dye degradation reaction, it can be considered as a pseudofirst-order with respect to the dye concentration (Deka et al., 2016):

$$
\ln \left(\frac{C_{t}}{C_{0}}\right) \text { or } \ln \left(\frac{A_{t}}{A_{0}}\right)=-k t,
$$

where $k$ is the degradation reaction apparent rate constant, $C_{0}, C_{t}, A_{0}$, and $A_{t}$ are $\mathrm{SG}$ dye concentration and absorbance

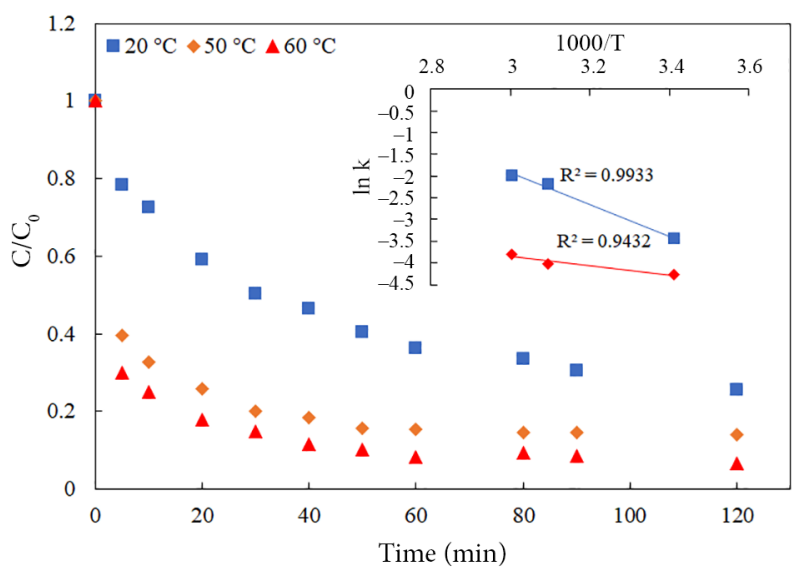

Figure 11. Effect of the reaction temperature on the kinetics of combined adsorption/catalytic degradation of SG dye. In the insert: Arrhenius plots for the first and second stages of reaction (from the data fitted to the pseudo-first-order kinetic model). Conditions: concentration of SG dye $100 \mathrm{mg} / \mathrm{L}$, dye solution volume $10 \mathrm{~mL}, 1 \mathrm{~mL} \mathrm{H}_{2} \mathrm{O}_{2}, 5 \mathrm{mg}$ GWTW catalyst, $\mathrm{pH} 3$ 
Table 2. The rate constants and thermodynamic activation parameters for the first and second stages of the combined process of adsorption and catalytic oxidation of SG dye

\begin{tabular}{|l|c|c|c|c|c|c|}
\hline \multicolumn{1}{|c|}{$\begin{array}{c}\text { Process } \\
\text { stage }\end{array}$} & $\mathrm{T},{ }^{\circ} \mathrm{C}$ & The rate constant $\mathrm{k}, \mathrm{min}^{-1}$ & $\begin{array}{c}E_{a,} \\
\mathrm{~kJ} \mathrm{~mol}{ }^{-1}\end{array}$ & $\begin{array}{c}\Delta H^{\#}, \\
\mathrm{~kJ} \mathrm{~mol}^{-1}\end{array}$ & $\begin{array}{c}\Delta S^{\#}, \\
\mathrm{~kJ} \mathrm{~mol}^{-1} \mathrm{~K}^{-1}\end{array}$ & $\begin{array}{c}\Delta G^{\#}, \\
\mathrm{~kJ} \mathrm{~mol}^{-1}\end{array}$ \\
\hline First & 20 & $0.0322\left(\mathrm{R}^{2}=0.9179\right)$ & 30.45 & 27.86 & -0.178 & 80.01 \\
\hline$(0-10 \mathrm{~min})$ & 50 & $0.1120\left(\mathrm{R}^{2}=0.8775\right)$ & & & & 85.35 \\
\hline & 60 & $0.1388\left(\mathrm{R}^{2}=0.8454\right)$ & & & 87.13 \\
Second & 20 & $0.0140\left(\mathrm{R}^{2}=0.9768\right)$ & 8.65 & 6.07 & -0.259 & 89.73 \\
$(10-50 \mathrm{~min})$ & 50 & $0.0181\left(\mathrm{R}^{2}=0.9739\right)$ & & & 92.32 \\
& 60 & $0.0222\left(\mathrm{R}^{2}=0.9746\right)$ & & & & \\
\hline
\end{tabular}

before reaction and at time $t$. The values of apparent rate constant $k$ were calculated at three temperatures from the slopes of the linear relationship $\ln \left(A_{t} / A_{0}\right)=f(t)$ and are listed in Table 2 . The rate constants of catalytic oxidation of the SG dye with $\mathrm{H}_{2} \mathrm{O}_{2}$ and GWTW nanostructures are highly dependent on temperature increases. As the temperature rises from $20^{\circ} \mathrm{C}$ to $60^{\circ} \mathrm{C}$ in a Fenton-like system, the SG dye degradation reaction rate increased more than fourfold in the first stage and by a factor of 1.6 in the second (Table 2).

Activation energies $E_{a}$ were determined from the slopes in the plots of linear dependence $\ln k=f(1 / T)$ according to Eq. (5) (Deka et al., 2016):

$$
\ln k=\ln A-E_{a} / R T \text {, }
$$

where $k$ is the degradation reaction rate constant, $A$ is Arrhenius constant, $E_{a}$ is activation energy $\left(\mathrm{J} \mathrm{mol}^{-1}\right), T$ is the absolute temperature $(\mathrm{K})$, and $R$ is the universal gas constant $\left(8.314472 \mathrm{~J} \mathrm{~K}^{-1} \mathrm{~mol}^{-1}\right)$.

The activation energy of the first stage of the SG dye degradation reaction is higher than that of the second stage and equals $30.45 \mathrm{~kJ} \mathrm{~mol}^{-1}$ (Table 2). Lin and Gurol (1998) studied the reaction of $\mathrm{H}_{2} \mathrm{O}_{2}$ with iron(III) oxide surface sites. The activation energy of $\mathrm{H}_{2} \mathrm{O}_{2}$ decomposition forming $\cdot \mathrm{OH}$ radicals has been determined to be $32.8 \mathrm{~kJ} \mathrm{~mol}^{-1}$.

The thermodynamic activation parameters of the SG dye catalytic degradation reaction were calculated using the linear form of the theoretical Eyring equation (Wilkins, 1974):

$$
\ln \left(\frac{k}{T}\right)=\ln \left(\frac{K_{B}}{h}\right)-\frac{\Delta H^{\#}}{R T}+\frac{\Delta S^{\#}}{R},
$$

where $k$ is the degradation reaction rate constant, $T$ is the absolute temperature $(\mathrm{K}), K_{B}$ is Boltzmann's constant $\left(1.381 \cdot 10^{-23} \mathrm{~J} \mathrm{~K}^{-1}\right), h$ is Plank constant $\left(6.626 \cdot 10^{-34} \mathrm{~J} \mathrm{~s}\right)$, $\Delta H^{\#}$ is activation enthalpy $\left(\mathrm{J} \mathrm{mol}^{-1}\right), \Delta S^{\#}$ is activation entropy $\left(\mathrm{J} \mathrm{mol}^{-1} \mathrm{~K}^{-1}\right)$, and $R$ is the universal gas constant (8.314472 $\mathrm{J} \mathrm{K}^{-1} \mathrm{~mol}^{-1}$ ).

When using the linear plots of relationship $\ln (k / T)=$ $f(1 / T)$ (Eq. (6)), changes in activation enthalpy $\left(\Delta H^{\#}\right)$ and entropy $\left(\Delta S^{\#}\right)$ were resolved from the slopes and intercepts, respectively. The changes of free energy of activation $\left(\Delta G^{\#}\right)$ were determined according to Eq. (7):

$$
\Delta G^{\#}=\Delta H^{\#}-T \Delta S^{\#} .
$$

The values of the $\Delta H^{\#}, \Delta S^{\#}$, and $\Delta G^{\#}$ for both stages of SG dye catalytic degradation reaction are presented in Table 2. The changes in activation enthalpy $\Delta H^{\#}>0$ reflect the endothermic character of the SG dye degradation reaction under sunlight in the presence of $\mathrm{H}_{2} \mathrm{O}_{2}$ and GWTW. Meanwhile, the low negative value of $\Delta S^{\#}$ reflects a more ordered structure of transition state and a slight decrease in the dispersal of energy at the interface of active centers of GWTW and solution (Saha \& Chowdhury, 2011). The values of changes of free energy of activation $\left(\Delta G^{\#}\right)$ at three different temperatures range from 80.01 to $92.32 \mathrm{~kJ} \mathrm{~mol}^{-1}$.

\subsection{SG dye removal mechanism}

Experimental results obtained using GWTW-SG dye adsorption systems have revealed the fact that dye removal is a strongly $\mathrm{pH}$-dependent process. The effect of solution $\mathrm{pH}$ on SG dye removal efficiency is related to GWTW surface protonation degree. The negative molecules of the anionic SG dye are attracted by positively charged GWTW surface according to Eq. (8):

$$
=\mathrm{FeOH}_{2}^{+}+\mathrm{A}^{-} \rightarrow=\mathrm{FeA}+\mathrm{H}_{2} \mathrm{O} \text {. }
$$

In the case of heterogeneous catalytic SG dye degradation, the adsorption of both SG dye and $\mathrm{H}_{2} \mathrm{O}_{2}$ takes place on the GWTW surface (Figure 12). The formation of radicals from $\mathrm{H}_{2} \mathrm{O}_{2}$ at the surface of GWTW and the process of catalytic SG dye degradation could be explained based on several steps (Pinto et al., 2012). After addition to the GWTW-SG dye system, $\mathrm{H}_{2} \mathrm{O}_{2}$ molecules adsorb on the GWTW surface rich in Fe(III):

$$
\begin{aligned}
& \mathrm{Fe}_{\text {surface }}{ }^{3+}+\mathrm{H}_{2} \mathrm{O}_{2}(\mathrm{aq}) \rightarrow \\
& {\left[\mathrm{Fe}_{\text {surface }}{ }^{3+} \mathrm{H}_{2} \mathrm{O}_{2} \text { (adsorbed) }\right] .}
\end{aligned}
$$

Adsorbed $\mathrm{H}_{2} \mathrm{O}_{2}$ molecules reduce $\mathrm{Fe}(\mathrm{III})$ to $\mathrm{Fe}(\mathrm{II})$ forming $\mathrm{Fe}^{2+}$ and $\mathrm{O}_{2}{ }^{--}$radicals:

$$
\begin{aligned}
& \left.\left[\mathrm{Fe}_{\text {surface }}{ }^{3+} \mathrm{H}_{2} \mathrm{O}_{2} \text { (adsorbed }\right)\right] \rightarrow \\
& \mathrm{Fe}_{\text {surface }}{ }^{2+}+\mathrm{O}_{2}{ }^{--}+2 \mathrm{H}^{+} .
\end{aligned}
$$

Generated $\mathrm{Fe}^{2+}$ react with the adsorbed $\mathrm{H}_{2} \mathrm{O}_{2}$ forming very active $\bullet \mathrm{OH}$ radicals $(\mathrm{E}=2.38 \mathrm{~V}$ at $\mathrm{pH} 3.0)$ :

$$
\begin{aligned}
& \mathrm{Fe}_{\text {surface }}{ }^{2+} \mathrm{H}_{2} \mathrm{O}_{2} \text { (adsorbed) } \rightarrow \\
& \mathrm{Fe}_{\text {surface }}{ }^{3+}+\cdot \mathrm{OH}+{ }^{-} \mathrm{OH} .
\end{aligned}
$$


- OH radicals attack and degrade SG dye molecules producing oxidation products:

$$
\cdot \mathrm{OH}+\mathrm{SG} \text { dye } \rightarrow \text { oxidation products. }
$$

It is known that dyes are cleaved when hydroxyl radicals react with organic molecules, mainly by removing hydrogen from the chemical bonds such as $\mathrm{C}-\mathrm{H}, \mathrm{N}-\mathrm{H}$, or $\mathrm{O}-\mathrm{H}$, or by adding hydrogen to the $\mathrm{C}=\mathrm{C}$ bonds or the aromatic rings (Pignatello et al., 2006). However, decolored water can contain a lot of small organic matter (Collivignarelli et al., 2019), so in the future, we plan to study organic matter degradation and determine the COD and TOC parameters.

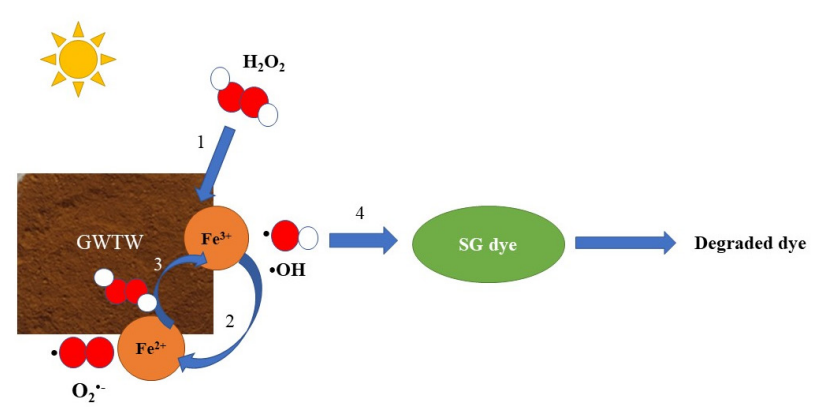

Figure 12. Scheme of the degradation of the SG dye using the heterogeneous Fenton-like catalyst prepared using sludge waste from groundwater treatment (GWTW)

\subsection{Comparison of the SG dye removal using raw and calcined GWTW}

It is well known that the studied material's physical properties and chemical composition influence its adsorption capacity and catalytic activity. For comparison, SG dye adsorption and catalytic degradation experiments were performed using untreated GWTW (W) and GWTW samples calcined at $800{ }^{\circ} \mathrm{C}(\mathrm{CW})$. As shown in Figure 13, the raw GWTW has a significantly higher potential to be used to remove SG dye from aqueous solutions compared to calcined samples. The SG dye removal by degradation (D) during the first $10 \mathrm{~min}$ is approximately four times higher in a system containing untreated GWTW (W). At $50{ }^{\circ} \mathrm{C}$ temperature, the removal efficiency is about $85 \%$ and $19 \%$ using untreated $(\mathrm{W})$ and calcined $(\mathrm{CW})$ samples of GWTW, respectively. The percentage of degraded SG dye at $50{ }^{\circ} \mathrm{C}$ temperature after $120 \mathrm{~min}$ of reaction increased up to $91 \%$ in the presence of $\mathrm{W}$ but only to $54 \%$ in the presence of CW. The adsorption capacity of the calcined material also decreased, but to a lesser extent compared to the decrease in catalytic activity in the SG dye degradation reaction. For both heterogeneous catalysts, untreated and calcined GWTW, higher degradation rates are observed at $50{ }^{\circ} \mathrm{C}$ temperature instead of lower $20^{\circ} \mathrm{C}$ temperature (Figure 13). In contrast to degradation, the efficiency of SG dye removal by adsorption decreases with increasing temperature: only slightly with untreated GWTW, but by almost a third with calcined GWTW.

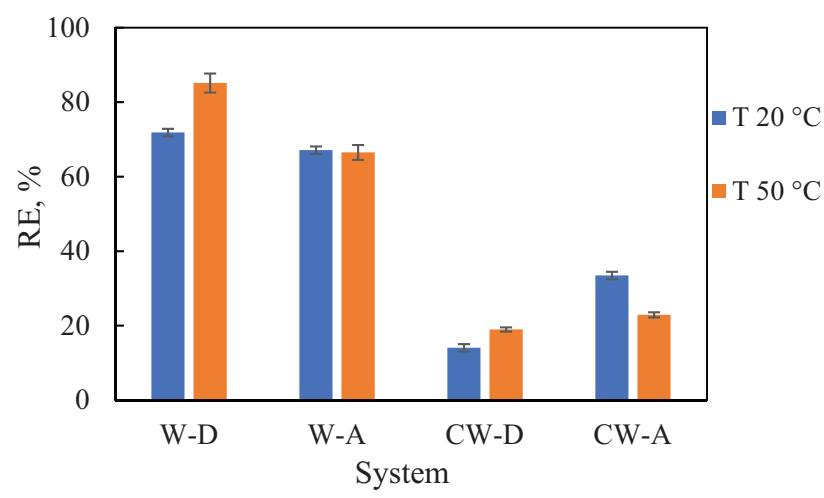

Figure 13. SG dye removal efficiency (RE) using raw (W) and calcined (CW) groundwater treatment waste (GWTW) for the dye degradation (D) or adsorption (A). Conditions: SG dye solution concentration $100 \mathrm{mg} / \mathrm{L}$, the volume of dye solution $10 \mathrm{~mL}, 5 \mathrm{mg} \mathrm{GWTW}, 1 \mathrm{~mL} \mathrm{H} \mathrm{H}_{2}$ for W-D and CW-D, pH 3, contact time $10 \mathrm{~min}$

The different actions of untreated and pre-calcined GWTW could be explained by changes in the solid phase's chemical composition and structural properties during the calcination process. As mentioned above, XPS analysis showed that the major components of untreated GWTW are hydrous ferric oxide, $\alpha-\mathrm{Fe}_{2} \mathrm{O}_{3}$ (hematite), and $\mathrm{Fe}(\mathrm{OH}$ ) $\mathrm{O}$ (goethite, lepidocrocite). While, according to the XRD analysis, the main phase of the calcined sample containing iron was maghemite $\left(\gamma-\mathrm{Fe}_{2} \mathrm{O}_{3}\right)$. Calcination of GWTW not only involves the transformation of iron(III) phases and a change in GWTW color (from brown to red), but also the remaining constituents can be converted to another form or removed at all. These changes may affect the catalytic activity of GWTW. Besides, the specific surface area of the amorphous GWTW is relatively higher when compared to its crystalline form leading to a higher adsorption capacity. The catalytic efficiency of the material is related to its adsorption ability (Xiao et al., 2018; Pinto et al., 2012). The larger the area of the GWTW, the richer it is in the number of active centers suitable for the interaction between the catalyst, $\mathrm{H}_{2} \mathrm{O}_{2}$, and the dye molecules.

The GWTW catalyst is suitable for reuse in the Fenton process because the weight loss of GWTW after one cycle is less than $0.2 \%$. Besides, the catalyst particles do not agglomerate after separation, so that GWTW can be reused with another portion of the dye solution and peroxide.

\subsection{Comparison of adsorption and catalytic properties of materials used for the dye removal}

The adsorbents of various types were tested for the adsorptive removal of metal complex anionic dye Sanodure Green (Figure 14). Batch experiments were carried out with the aim to compare the dye removal rate and removal capacity using different adsorbents. As can be seen from Figure 14, the adsorptive properties of GWTW are comparable with those of the powdered activated carbon. More than $96 \%$ and $88 \%$ of the dye color can be removed in the first 3 min with the aid of GWTW, and Norit PK 1-3 activated carbon, respectively. 


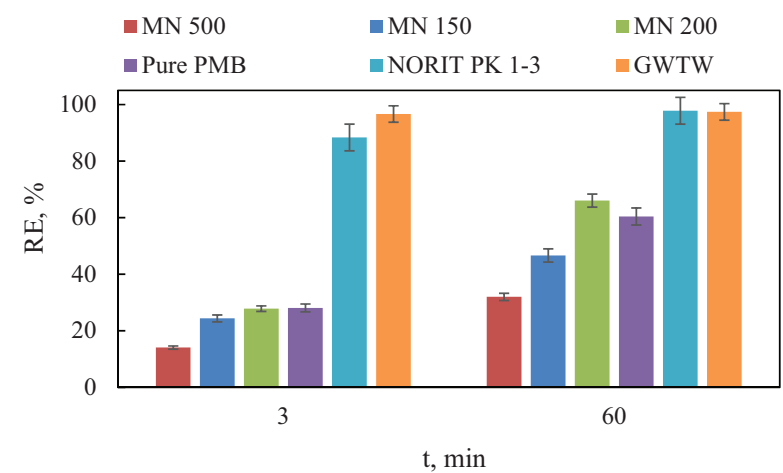

Figure 14. Comparison of SG dye adsorption capacity in various adsorbents. Conditions: SG dye solution $\mathrm{pH} 2$, adsorbent dose $4 \mathrm{~g} / \mathrm{L}$, temperature $20^{\circ} \mathrm{C}$

When polymeric materials (macroporous resins $\mathrm{MN}$ 500, MN 150, MN 200, and mixed bed resin PMB) are used as adsorbents, only $14-28 \%$ of the color of the dye solution can be removed at the same time. Over time, their adsorption capacities toward SG dye increase, but even after $60 \mathrm{~min}$, they do not equal the adsorption capacities of GWTW and activated carbon. In addition, the advantage of the GWTW is that it can be used both as an adsorbent and as a catalyst. The catalytic activity of GWTW in the Fenton-like reaction was evaluated considering the data presented in the literature (Table 3). Despite the difference in the operating parameters and the variety of the studied dyes, we can see that the degradation efficiencies of GWTW and the other iron-rich compounds are at a similar level. The advantage of the catalyst used in this study is that specific preparation is not required. Although the initial concentration of the SG dye solution was relatively high and reached $100 \mathrm{mg} / \mathrm{L}, 92 \%$ degradation was achieved within 50 min (Table 3 ).

Table 3. Comparison of catalytic activity of the GWTW with the other Fe(III) containing catalysts reported in the literature (COD chemical oxygen demand; RE - removal efficiency)

\begin{tabular}{|c|c|c|c|c|}
\hline Reference & Pollutant & Catalyst & Optimum conditions and operating parameters & Results \\
\hline $\begin{array}{l}\text { Huang et al., } \\
2011\end{array}$ & $\begin{array}{l}\text { Dispersed Orange } \\
288\end{array}$ & $\begin{array}{l}\text { Nano-iron oxides/ } \\
\text { goldmine waste- } \\
\text { solid }\end{array}$ & $\begin{array}{l}3.0 \mathrm{~g} \text { catalyst waste-solid, } \\
100 \mathrm{~mL} \text { of dye solution, } \\
5 \mathrm{~mL} \text { of } \mathrm{H}_{2} \mathrm{O}_{2} \\
\text { Temperature } 30^{\circ} \mathrm{C}, \\
\mathrm{pH}<1 \\
\text { Time } 2 \mathrm{~h}\end{array}$ & $\begin{array}{l}\text { COD removal } \\
\text { efficiency } \\
68.6 \%\end{array}$ \\
\hline Guz et al., 2014 & $\begin{array}{l}\text { Crystal Violet } \\
(\mathrm{CV})\end{array}$ & $\begin{array}{l}\text { Iron modified } \\
\text { montmorillo-nite } \\
(\mathrm{MMT}-\mathrm{Fe})\end{array}$ & $\begin{array}{l}1.5 \mathrm{~g} / \mathrm{L} \text { MMT-Fe, } \\
100 \mathrm{~mL} 0.060 \mathrm{mM} \mathrm{CV} \text {, } \\
30 \% \mathrm{H}_{2} \mathrm{O}_{2} \\
\text { Temperature } 25^{\circ} \mathrm{C}, \\
\text { Time } 2 \mathrm{~h} \text {, } \\
300 \mathrm{~W} \text { solar lamp }\end{array}$ & RE 99.9\% \\
\hline $\begin{array}{l}\text { Zheng et al., } \\
2015\end{array}$ & $\begin{array}{l}\text { Congo Red (CR), } \\
\text { Eosin Red (ER), } \\
\text { Methylene Blue } \\
\text { (MB) }\end{array}$ & $\alpha-\mathrm{Fe}_{2} \mathrm{O}_{3}$ & $\begin{array}{l}0.2 \mathrm{~g} \alpha-\mathrm{Fe}_{2} \mathrm{O}_{3} \text {, } \\
200 \mathrm{~mL} \text { dye solutions }(10 \mathrm{mg} / \mathrm{L}) \text {, } \\
\text { Room temperature, } \\
\text { Time } 50 \mathrm{~min}, \\
\text { Visible light irradiation }\end{array}$ & $\begin{array}{l}\mathrm{RE} \text { of } \mathrm{MB} \\
(57 \%)<\mathrm{ER} \\
(63 \%)<\mathrm{CR}(93 \%)\end{array}$ \\
\hline $\begin{array}{l}\text { Xiao et al., } \\
2018\end{array}$ & Acid Red G & $\alpha-\mathrm{Fe}_{2} \mathrm{O}_{3}$ & $\begin{array}{l}0.1 \mathrm{~g} \alpha-\mathrm{Fe}_{2} \mathrm{O}_{3} \\
0.1 \mathrm{~L} 50 \mathrm{mg} / \mathrm{L} \text { dye, } \\
0.3 \mathrm{~mL} \text { of } \mathrm{H}_{2} \mathrm{O}_{2} \text { solution }(30 \mathrm{wt} \%) \text {, } \\
\text { pH } 2 \text {, } \\
\text { Time } 90 \mathrm{~min}, \\
\text { LED lamp }(\lambda=420 \mathrm{~nm}) \text { irradiation }\end{array}$ & RE $98 \%$ \\
\hline $\begin{array}{l}\text { Rubeena et al., } \\
2018\end{array}$ & Acid Red 1 (AR1) & $\begin{array}{l}\text { Iron loaded rice } \\
\text { husk biochar } \\
\text { (Fe-RHB) and coir } \\
\text { pith biochar } \\
\text { (Fe-CPB) }\end{array}$ & $\begin{array}{l}5 \mathrm{~g} / \mathrm{L} \text { and } 4 \mathrm{~g} / \mathrm{L} \text { for } \mathrm{Fe}-\mathrm{RHB} \text { and } \mathrm{Fe}-\mathrm{CPB} \text {, } \\
\text { respectively, } \\
200 \mathrm{~mL} \text { dye }(50 \mathrm{mg} / \mathrm{L}), \\
16 \mathrm{mM} \mathrm{H}_{2} \mathrm{O}_{2}, \\
\text { The temperature } 30^{\circ} \mathrm{C} \text {, } \\
\mathrm{pH} \mathrm{3,} \\
\text { Time } 120 \mathrm{~min}\end{array}$ & $\begin{array}{l}\text { RE 97.6\% } \\
(\mathrm{Fe}-\mathrm{RHB}) \text { and } \\
99.1 \%(\mathrm{Fe}-\mathrm{CPB})\end{array}$ \\
\hline $\begin{array}{l}\text { Domacena } \\
\text { et al., } 2020\end{array}$ & $\begin{array}{l}\text { Methyl Orange } \\
(\mathrm{MO})\end{array}$ & $\alpha-\mathrm{Fe}_{2} \mathrm{O}_{3}$ powders & $\begin{array}{l}30 \mathrm{mg} \mathrm{a}-\mathrm{Fe}_{2} \mathrm{O}_{3} \text { powders, } \\
30 \mathrm{ml} 2.5 \mathrm{ppm} \mathrm{MO}, \\
30 \mu \mathrm{L} \mathrm{H}_{2} \mathrm{O}_{2} \\
\text { Time } 2 \mathrm{~h}, \\
\text { UVC lamp } 10 \times 2 \mathrm{~W}, \\
2.5 \mathrm{ppm}\end{array}$ & RE $76.5 \%$ \\
\hline
\end{tabular}


End of Table 3

\begin{tabular}{|c|c|c|c|c|}
\hline Reference & Pollutant & Catalyst & Optimum conditions and operating parameters & Results \\
\hline $\begin{array}{l}\text { Nadeem et al., } \\
2020\end{array}$ & Synozol Red & $\begin{array}{l}\mathrm{ZnFe}_{2} \mathrm{O}_{4} \text { and } \\
\text { graphene oxide } \\
\text { based } \mathrm{ZnFe}_{2} \mathrm{O}_{4} \\
\text { composite }\end{array}$ & $\begin{array}{l}75 \mathrm{mg} / \mathrm{L} \text { for } \mathrm{ZnFe}_{2} \mathrm{O}_{4} \text { and } 50 \mathrm{mg} / \mathrm{L} \text { for } \mathrm{GO}- \\
\mathrm{ZnFe}_{2} \mathrm{O}_{4} \\
\mathrm{H}_{2} \mathrm{O}_{2} \text { dose }=27 \mathrm{mM} \text {, } \\
\mathrm{pH}=3 \text {, } \\
\text { Irradiation time }=60 \mathrm{~min}\end{array}$ & RE $57 \%$ and $94 \%$ \\
\hline Xu et al., 2021 & $\begin{array}{l}\text { Methylene Blue } \\
\text { (MB) }\end{array}$ & $\alpha-\mathrm{Fe}_{2} \mathrm{O}_{3-\mathrm{x}}$ & $\begin{array}{l}10 \mathrm{mg} \alpha-\mathrm{Fe}_{2} \mathrm{O}_{3-\mathrm{x}} \\
50 \mathrm{~mL} \text { of } \mathrm{MB} \text { aqueous solution }(0.02 \mathrm{mM}) \text {, } \\
255 \mu \mathrm{L} \text { of } \mathrm{H}_{2} \mathrm{O}_{2} \text { solution }(30 \mathrm{wt} \%), \\
\text { Room temperature, } \\
\text { pH } 2.0, \\
\text { Time } 40 \mathrm{~min} \text {, } \\
300 \mathrm{~W} \text { xenon lamp }\end{array}$ & RE $82 \%$ \\
\hline $\begin{array}{l}\text { Nasuha et al., } \\
2021\end{array}$ & $\begin{array}{l}\text { Methylene Blue } \\
\text { (MB), Acid Blue } \\
29 \text { (AB29) }\end{array}$ & $\begin{array}{l}\text { Slag activated } \\
\text { by sulfuric acid } \\
(\text { S-EAF) }\end{array}$ & $\begin{array}{l}\text { S-EAF dosage } 0.04 \mathrm{~g}(\mathrm{AB} 29) \text { and } 0.02 \mathrm{~g}(\mathrm{MB}) \\
\mathrm{C}_{0}(\text { dye })=50 \mathrm{mg} / \mathrm{L} \text {, } \\
6 \mathrm{mM}(\mathrm{AB} 29) \text { and } 8 \mathrm{mM}(\mathrm{MB}) \mathrm{H}_{2} \mathrm{O}_{2} \\
\text { concentration, } \\
\text { Temperature } 30^{\circ} \mathrm{C} \\
\mathrm{pH}=4.5\end{array}$ & RE $95 \%$ and $82 \%$ \\
\hline This study & $\begin{array}{l}\text { Sanodure Green } \\
\text { LWN }\end{array}$ & $\begin{array}{l}\text { Groundwater } \\
\text { treatment waste } \\
\text { (GWTW) }\end{array}$ & $\begin{array}{l}5 \mathrm{mg} \text { GWTW catalyst, } \\
10 \mathrm{~mL} \mathrm{SG} \text { dye }(100 \mathrm{mg} / \mathrm{L}) \text {, } \\
1 \mathrm{~mL} \mathrm{H} \mathrm{O}_{2}(30 \mathrm{wt} \%), \\
\text { Temperature } 50{ }^{\circ} \mathrm{C}, \\
\text { pH 3, } \\
\text { Time } 50 \mathrm{~min}\end{array}$ & RE $92 \%$ \\
\hline
\end{tabular}

\section{Conclusions}

Groundwater treatment waste (GWTW) has been successfully utilized for the decoloration of the metal complex dye Sanodure green LWN solutions due to its unique natural properties. The raw GWTW was more suitable for dye removal than calcined at $800{ }^{\circ} \mathrm{C}$ temperature. The high decoloration rate (up to $70 \%$ in the first $5 \mathrm{~min}$ ) was achieved by a combined adsorption/degradation process using GWTW as adsorbent and catalyst, $\mathrm{H}_{2} \mathrm{O}_{2}$ as oxidant, and natural sunlight as an energy source. Adsorption or noncatalytic peroxidation alone was less effective in removing SG dye. The acidic medium ( $\mathrm{pH} 2-3$ ) was more favorable not only for the adsorption but also for the degradation of SG dye. The solution decoloration rate increased with an increase in temperature. The process of SG dye catalytic degradation can be divided into several kinetic regions with different rate constants and activation energy values. The dye degradation reaction is endothermic in nature and is controlled by the enthalpy of activation.

This study concludes that the usage of GWTW could be considered a sustainable way for the pre-treatment of dye-contaminated wastewater before it enters the wastewater treatment plant.

\section{References}

Albrektienè, R., Karaliūnas, K., \& Bazienè, K. (2019). Sustainable reuse of groundwater treatment iron sludge for organic matter removal from river Neris water. Sustainability, 11(3), 639-654. https://doi.org/10.3390/su11030639

Ali, M. E. M., Gad-Allah, T. A., \& Badawy, M. I. (2013). Heterogeneous Fenton process using steel industry wastes for me- thyl orange degradation. Applied Water Science, 3, 263-270. https://doi.org/10.1007/s13201-013-0078-1

Aragaw, T. A., Bogale, F. M., \& Aragaw, B. A. (2021). Iron-based nanoparticles in wastewater treatment: A review on synthesis methods, applications, and removal mechanisms. Journal of Saudi Chemical Society, 25(8), 101280.

https://doi.org/10.1016/j.jscs.2021.101280

Arora, C., Kumar, P., Soni, S., Mittal, J., Mittal, A., \& Singh, B. (2020). Efficient removal of malachite green dye from aqueous solution using Curcuma caesia based activated carbon. Desalination and Water Treatment Science and Engineering, 195, 341-352. https://doi.org/10.5004/dwt.2020.25897

Azha, S. F., Shahadat, M., Ismail, S., Ali, S. W., \& Ahammad, S. Z. (2021). Prospect of clay-based flexible adsorbent coatings as cleaner production technique in wastewater treatment, challenges, and issues: A review. Journal of the Taiwan Institute of Chemical Engineers, 120, 178-206.

https://doi.org/10.1016/j.jtice.2021.03.018

Babatunde, A. O., \& Zhao, Y. O. (2007). Constructive approaches toward water treatment works sludge management: An international review of beneficial reuses. Critical Reviews in Environmental Science and Technology, 37(2), 129-164. https://doi.org/10.1080/10643380600776239

Banazadeh, A., Salimi, H., Khaleghi, M., \& Shafiei-Haghighi, S. (2016). Highly efficient degradation of hazardous dyes in aqueous phase by supported palladium nanocatalyst-a green approach. Journal of Environmental Chemical Engineering, 4(2), 2178-2182. https://doi.org/10.1016/j.jece.2015.09.007

Bartošová, A., Blinová, L., Sirotiak, M., \& Michalíková, A. (2017). Usage of FTIR-ATR as non-destructive analysis of selected toxic dyes. Research Papers Faculty of Materials Science and Technology Slovak University of Technology, 25(40), 103-111. https://doi.org/10.1515/rput-2017-0012

Bello, M. M., \& Raman, A. A. A. (2019). Synergy of adsorption and advanced oxidation processes in recalcitrant wastewater 
treatment. Environmental Chemistry Letters, 17, 1125-1142. https://doi.org/10.1007/s10311-018-00842-0

Benetoli, L. O. de B., Cadorin, B. M., Postiglione, C. da S., de Souza, I. G., \& Debacher, N. A. (2011). Effect of temperature on methylene blue decolorization in aqueous medium in electrical discharge plasma reactor. Journal of Brazilian Chemical Society, 22(9), 1669-1678.

https://doi.org/10.1590/S0103-50532011000900008

Bhat, A. P., \& Gogate, P. R. (2021). Degradation of nitrogencontaining hazardous compounds using advanced oxidation processes: A review on aliphatic and aromatic amines, dyes, and pesticides. Journal of Hazardous Materials, 403, 123657. https://doi.org/10.1016/j.jhazmat.2020.123657

Bokare, A. D., \& Choi, W. (2014). Review of iron-free Fentonlike systems for activating $\mathrm{H}_{2} \mathrm{O}_{2}$ in advanced oxidation processes. Journal of Hazardous Materials, 275, 121-135. https://doi.org/10.1016/j.jhazmat.2014.04.054

Chang, Ch.-Ch., Chiang, F.-Ch., Chen, Sh.-M., Thangavelu, K., \& Yang, H.-J. (2016). Studies on electrochemical oxidation of aluminum and dyeing in various additives towards industrial applications. International Journal of Electrochemical Science, $11,2142-2150$.

Clariant. (2014). Aluminum finishing. Specific color solutions. Clariant International Ltd.

Clariant. (2020). Sanodure Green LWN safety data sheet. https:// www.clariant.com/en/Solutions/Products/2014/03/18/17/07/ Sanodure-Green-LWN

Collivignarelli, M. C., Abb, A., Miino, M. C., \& Damiani, S. (2019). Treatments for color removal from wastewater: State of the art. Journal of Environmental Management, 236, 727745. https://doi.org/10.1016/j.jenvman.2018.11.094

Deka, P., Hazarika, A., Deka, R. C., \& Bharali, P. (2016). Influence of $\mathrm{CuO}$ morphology on the enhanced catalytic degradation on methylene blue and methyl orange. RSC Advances, 6, 95292-95305. https://doi.org/10.1039/C6RA20173C

Diliūnas, J., Jurevičius, A., \& Zuzevičius, A. (2006). Formation of iron compounds in the Quaternary groundwater of Lithuania. Geologija, 55, 66-73.

Domacena, A. M. G., Aquino, C. L. E., \& Balela, M. D. L. (2020). Photo-Fenton degradation of methyl orange using hematite $\left(\alpha-\mathrm{Fe}_{2} \mathrm{O}_{3}\right.$ ) of various morphologies. Materials Today: Proceedings, 22, 248-254. https://doi.org/10.1016/j.matpr.2019.08.095

Dzombak, D. A., \& Morel, F. M. M. (1990). Surface complexation modeling: Hydrous Ferric Oxide. John Wiley \& Sons.

Garrido-Ramírez, E. G., Theng, B. K. G., \& Mora, M. L. (2010). Clays and oxide minerals as catalysts and nanocatalysts in Fenton-like reactions - A review. Applied Clay Science, 47(34), 182-192. https://doi.org/10.1016/j.clay.2009.11.044

Grosvenor, A. P., Kobe, B. A., Biesinger, M. C., \& McIntyre, N. S. (2004). Investigation of multiplet splitting of Fe 2p XPS spectra and bonding in iron compounds. Surface and Interface Analysis, 36(12), 1564-1574. https://doi.org/10.1002/sia.1984

Gupta, V. K., Agarwal, S., Ahmad, R., Mirza, A., \& Mittal, J. (2020). Sequestration of toxic congo red dye from aqueous solution using ecofriendly guar gum/activated carbon nanocomposite. International Journal of Biological Macromolecules, 158, 1310-1318.

https://doi.org/10.1016/j.ijbiomac.2020.05.025

Guz, L., Curutchet, G., Torres Sánchez, R. M., \& Candal, R. (2014). Adsorption of crystal violet on montmorillonite (or iron modified montmorillonite) followed by degradation through Fenton or photo-Fenton type reactions. Journal of Environmental Chemical Engineering, 2(4), 2344-2351. https://doi.org/10.1016/j.jece.2014.02.007
Haddad, B., Mittal, A., Mittal, J., Paolone, A., Villemin, D., Debdab, M., Mimanne, G., Habibi, A., Hamidi, Z., Boumediene, M., \& Belarbi, E.-h. (2021). Synthesis and characterization of Egg shell (ES) and Egg shell with membrane (ESM) modified by ionic liquids. Chemical Data Collections, 33, 100717. https://doi.org/10.1016/j.cdc.2021.100717

Heber, T. (2015). Weather fast adsorptive dyeing of anodized aluminum for outdoor applications [Conference presentation]. 2015 Anodizing Conference, San Diego, California.

Horáková, M., Klementová, Š., Kříž, P., Balakrishna, S. K., Špatenka, P., Golovko, O., Hájková, P., \& Exnar, P. (2014). The synergistic effect of advanced oxidation processes to eliminate resistant chemical compounds. Surface and Coatings Technology, 241, 154-158.

https://doi.org/10.1016/j.surfcoat.2013.10.068

Hou, P., Shi, C., Wu, L., \& Hou, X. (2016). Chitosan/hydroxyapatite/ $\mathrm{Fe}_{3} \mathrm{O}_{4}$ magnetic composite for metal-complex dye AY220 removal: Recyclable metal-promoted Fenton-like degradation. Microchemical Journal, 128, 218-225.

https://doi.org/10.1016/j.microc.2016.04.022

Huang, M., Zhao, K., Zhang, M., Chen, Sh., Xu, W., Ye, Y., Fu, W., Wei, Y., Qiu, Z., \& Sun, F. (2011). Removal of disperse dyes from wastewater by nano-iron modified goldmine waste-solid assisted AOPs. Procedia Engineering, 18, 358-362. https://doi.org/10.1016/j.proeng.2011.11.057

Jabeen, A., \& Bhatti, H. N. (2021). Adsorptive removal of reactive green 5 (RG-5) and direct yellow 50 (DY-50) from simulated wastewater by Mangifera indica seed shell and its magnetic composite: Batch and Column study. Environmental Technology \& Innovation, 23, 101685.

https://doi.org/10.1016/j.eti.2021.101685

Kan, T., Strezov, V., Evans, T., \& Nelson, P. (2016). Analysis of water produced during thermal decomposition of goethitic iron ore. International Journal of Chemical Engineering and Applications, 7(5), 327-330.

https://doi.org/10.18178/ijcea.2016.7.5.599

Katsoukis, G., Jun Jo, W., \& Frei, H. (2019). Structure and orientation of molecular wires embedded in ultrathin silica membrane for artificial photosynthesis elucidated by polarized FT-IRRAS. Journal of Physical Chemistry C, 123(31), 18905-18913. https://doi.org/10.1021/acs.jpcc.9b02523

Kausar, A., Naeem, K., Iqbal, M., Nazli, Z.-H., Bhatti, H. N., Ashraf, A., Nazir, A., Kusuma, H. S., \& Khan, M. I. (2021). Kinetics, equilibrium and thermodynamics of dyes adsorption onto modified chitosan: A review. Zeitschrift für Physikalische Chemie. https://doi.org/10.1515/zpc-2019-1586

Lai, C., Shi, X., Li, L., Cheng, M., Liu, X., Liu, S., Li, B., Yi, H., Qin, L., Zhang, M., \& An, N. (2021). Enhancing iron redox cycling for promoting heterogeneous Fenton performance: A review. Science of the Total Environment, 775, 145850. https://doi.org/10.1016/j.scitotenv.2021.145850

Leiviskä, T., Leskelä, T., \& Tanskanen, J. (2019). Effect of alkali regeneration on pore characteristics and performance of ferric oxyhydroxide and akaganéite sorbents. Journal of Water Process Engineering, 31, 100838. https://doi.org/10.1016/j.jwpe.2019.100838

Li, X., Xiao, B., Wu, M., Wang, L., Chen, R., Wei, Y., \& Liu, H. (2020). In-situ generation of multi-homogeneous/heterogeneous Fe-based Fenton catalysts toward rapid degradation of organic pollutants at near neutral $\mathrm{pH}$. Chemosphere, 245, 125663. https://doi.org/10.1016/j.chemosphere.2019.125663

Li, Y., \& Zhang, F.-S. (2010) Catalytic oxidation of Methyl Orange by an amorphous $\mathrm{FeOOH}$ catalyst developed from a high iron-containing fly ash. Chemical Engineering Journal, 158(2), 148-153. https://doi.org/10.1016/j.cej.2009.12.021 
Lin, S.-S., \& Gurol, M. D. (1998). Catalytic decomposition of hydrogen peroxide on iron oxide: Kinetics, mechanism, and implications. Environmental Science and Technology, 32(10), 1417-1423. https://doi.org/10.1021/es970648k

Luo, H., Zeng, Y., He, D., \& Pan, X. (2021). Application of ironbased materials in heterogeneous advanced oxidation processes for wastewater treatment: A review. Chemical Engineering Journal, 407, 127191.

https://doi.org/10.1016/j.cej.2020.127191

Mariyam, A., Mittal, J., Sakina, F., Baker, R. T., \& Sharma, A. K. (2021a). Adsorption behaviour of Chrysoidine R dye on a metal/halide-free variant of ordered mesoporous carbon. Desalination and Water Treatment Science and Engineering, 223, 425-433. https://doi.org/10.5004/dwt.2021.27147

Mariyam, A., Mittal, J., Sakina, F., Baker, R. T., Sharma, A. K., \& Mittal, A. (2021b). Efficient batch and Fixed-Bed sequestration of a basic dye using a novel variant of ordered mesoporous carbon as adsorbent. Arabian Journal of Chemistry, 14(6), 103186. https://doi.org/10.1016/j.arabjc.2021.103186

McIntyre, N. S., \& Zetaruk, G. (1977). X-ray photoelectron spectroscopic studies of iron oxides. Analytical Chemistry, 49(11), 1521-1529. https://doi.org/10.1021/ac50019a016

Miao, X., Dai, H., Chen, J., \& Zhu, J. (2018). The enhanced method of hydroxyl radical generation in the heterogeneous UV-Fenton system with $\alpha-\mathrm{FeOOH}$ as catalyst. Separation and Purification Technology, 200, 36-43.

https://doi.org/10.1016/j.seppur.2018.02.012

Mittal, A., \& Mittal, J. (2015). Hen feather: A remarkable adsorbent for dye removal. In S. K. Sharma (Ed.), Green chemistry for dyes removal from wastewater: Research trends and applications (pp. 409-457). Scrivener Publishing LLC. https://doi.org/10.1002/9781118721001.ch11

Mittal, J. (2020). Permissible synthetic food dyes in India. Resonance, 25, 567-577.

https://doi.org/10.1007/s12045-020-0970-6

Montoya-Bautista, C. V., Avella, E., Ramírez-Zamora, R.-M., \& Schouwenaars, R. (2019). Metallurgical wastes employed as catalysts and photocatalysts for water treatment: A review. Sustainability, 11(9), 2470-2486.

https://doi.org/10.3390/su11092470

Moradi, M., Elahinia, A., Vasseghian, Y., Dragoi, E.-N., Omidi, F., \& Khaneghah, A. M. (2020). A review on pollutants removal by Sono-photo -Fenton processes. Journal of Environmental Chemical Engineering, 8(5), 104330.

https://doi.org/10.1016/j.jece.2020.104330

Nadeem, N., Zahid, M., Tabasum, A., Mansha, A., Jilani, A., Bhatti, I. A., \& Bhatti, H. N. (2020). Degradation of reactive dye using heterogeneous photo-Fenton catalysts: $\mathrm{Zn}$ $\mathrm{Fe}_{2} \mathrm{O}_{4}$ and $G O-\mathrm{ZnFe}_{2} \mathrm{O}_{4}$ composite. Materials Research Express, 7(1), 015519. https://doi.org/10.1088/2053-1591/ab66ee

Nasuha, N., Hameed, B. H., \& Okoye, P. U. (2021). Dark-Fenton oxidative degradation of methylene blue and acid blue 29 dyes using sulfuric acid-activated slag of the steel-making process. Journal of Environmental Chemical Engineering, 9(1), 104831. https://doi.org/10.1016/j.jece.2020.104831

Neyens, E., \& Baeyens, J. (2003). A review of classic Fenton's peroxidation as an advanced oxidation technique. Journal of Hazardous Materials, 98(1-3), 33-50.

https://doi.org/10.1016/S0304-3894(02)00282-0

Nguyen, T. T., Huynh, K. A., Padungthon, S., Pranudta, A., Amonpattaratkit, P., Tran, L. B., Phan, P. T., \& Nguyen, N. H. (2021). Synthesis of natural flowerlike iron-alum oxide with special interaction of Fe-Si-Al oxides as an effective catalyst for heterogeneous Fenton process. Journal of Environmental
Chemical Engineering, 9(4), 105732.

https://doi.org/10.1016/j.jece.2021.105732

Noreen, S., Bhatti, H. N., Iqbal, M., Hussain, F., \& Sarim, F. M. (2020). Chitosan, starch, polyaniline and polypyrrole biocomposite with sugarcane bagasse for the efficient removal of Acid Black dye. International Journal of Biological Macromolecules, 147, 439-452. https://doi.org/10.1016/j.ijbiomac.2019.12.257

Novoselova, L. Y. (2013). Composition, structure and sorbability of the thermally treated water deironing precipitate with respect to carbon monoxide. Powder Technology, 243, 149-153. https://doi.org/10.1016/j.powtec.2013.03.032

Ociński, D., Jacukowicz-Sobala, I., Mazur, P., Raczyk, J., \& Kociołek-Balawejder, E. (2016). Water treatment residuals containing iron and manganese oxides for arsenic removal from water - Characterization of physicochemical properties and adsorption studies. Chemical Engineering Journal, 294, 210-221. https://doi.org/10.1016/j.cej.2016.02.111

Oliveira, C., Santosa, M. S. F., Maldonado-Hódar, F. J., Schaule, G., Alves, A., \& Madeira, L. M. (2012). Use of pipe deposits from water networks as novel catalysts in paraquat peroxidation. Chemical Engineering Journal, 210, 339-349. https://doi.org/10.1016/j.cej.2012.09.001

Oller, I., Malato, S., \& Sanchez-Perez, J. A. (2011). Combination of advanced oxidation processes and biological treatments for wastewater decontamination - A review. Science of Total Environment, 409(20), 4141-4166. https://doi.org/10.1016/j.scitotenv.2010.08.061

Ong, D. C., Kan, C. Ch., Mae, Sh., Pingul-Ong, B., \& de Luna, M. D. G. (2017). Utilization of groundwater treatment plant (GWTP) sludge for nickel removal from aqueous solutions: Isotherm and kinetic studies. Journal of Environmental Chemical Engineering, 5(6), 5746-5753. https://doi.org/10.1016/j.jece.2017.10.046

Pal, S., Singh, P. N., Verma, A., Kumar, A., Tiwary, D., Prakash, R., \& Sinha, I. (2020). Visible light photo-Fenton catalytic properties of starch functionalized iron oxyhydroxide nanocomposites. Environmental Nanotechnology, Monitoring \& Management, 14, 100311.

https://doi.org/10.1016/j.enmm.2020.100311

Paredes-Laverde, M., Salamanca, M., Diaz-Corrales, J. D., Flórez, E., Silva-Agredo, J., \& Torres-Palma, R. A. (2021). Understanding the removal of an anionic dye in textile wastewaters by adsorption on $\mathrm{ZnCl}_{2}$ activated carbons from rice and coffee husk wastes: A combined experimental and theoretical study. Journal of Environmental Chemical Engineering, 9(4), 105685. https://doi.org/10.1016/j.jece.2021.105685

Patel, A., Soni, S., Mittal, J., Mittal, A., \& Arora, C. (2021). Sequestration of crystal violet from aqueous solution using ash of black turmeric rhizome. Desalination and Water Treatment, 220, 342-352. https://doi.org/10.5004/dwt.2021.26911

Prati, S., Milosevic, M., Sciutto, G., Bonacini, I., Kazarian, S. G., \& Mazzeo, R. (2016). Analyses of trace amounts of dyes with a new enhanced sensitivity FTIR spectroscopic technique: MUATR (metal underlayer ATR spectroscopy). Analytica Chimica Acta, 941, 67-79. https://doi.org/10.1016/j.aca.2016.09.005

Perrotti, T. C., Freitas, N. S., Alzamora, M., Sánchez, D. R., \& Carvalho, N. M. F. (2019). Green iron nanoparticles supported on amino-functionalized silica for removal of the dye methyl orange. Journal of Environmental Chemical Engineering, 7(4), 103237. https://doi.org/10.1016/j.jece.2019.103237

Pignatello, J. J., Oliveros, E., \& Mackay, A. (2006). Advanced oxidation processes for organic contaminant destruction based on the Fenton reaction and related chemistry. Critical Reviews in Environmental Science and Technology, 36(1), 1-84. https://doi.org/10.1080/10643380500326564 
Pinto, I. S. X., Pacheco, P. H. V. V., Coelho, J. V., Lorençon, E., Ardisson, J. D., Fabris, J. D., de Souza, P. P., Krambrock, K. W. H., Oliveira, L. C. A., \& Pereira, M. C. (2012). Nanostructured $\delta$-FeOOH: An efficient Fenton-like catalyst for the oxidation of organics in water. Applied Catalysis B: Environmental, 119-120, 175-182.

https://doi.org/10.1016/j.apcatb.2012.02.026

Prucek, R., Hermanek, M., \& Zbořil, R. (2009). An effect of iron(III) oxides crystallinity on their catalytic efficiency and applicability in phenol degradation - A competition between homogeneous and heterogeneous catalysis. Applied Catalysis A: General, 366(2), 325-332.

https://doi.org/10.1016/j.apcata.2009.07.019

Rubeena, K. K., Prasad Reddy, P. H., Laiju, A. R., \& Nidheesh, P. V. (2018). Iron impregnated biochars as heterogeneous Fenton catalyst for the degradation of acid red 1 dye. Journal of Environmental Management, 226, 320-328. https://doi.org/10.1016/j.jenvman.2018.08.055

Saha, P., \& Chowdhury, Sh. (2011). Insight into adsorption thermodynamics. In M. Tadashi (Ed.), Thermodynamics, CC-BYNC-SA (pp. 349-364). InTech. https://doi.org/10.5772/13474

Saharan, S., Kumar, V., Mittal, J., Sharma, V., \& Sharma, A. K. (2021). Efficient ultrasonic assisted adsorption of organic pollutants employing bimetallic-carbon nanocomposites. Separation Science and Technology, 56(17), 2895-2908. https://doi.org/10.1080/01496395.2020.1866608

Sanchis, R., Dejoz, A., Vázquez, I., Vilarrasa-García, E., JiménezJiménez J., Rodríguez-Castellón, E., Nieto, J. M. L., \& Solsona, B. (2019). Ferric sludge derived from the process of water purification as an efficient catalyst and/or support for the removal of volatile organic compounds. Chemosphere, 219, 286-295. https://doi.org/10.1016/j.chemosphere.2018.12.002

Santos, V. P., Pereira, M. F. R., Faria, P. C. C., \& Órfão, J. J. M. (2009). Decolourisation of dye solutions by oxidation with $\mathrm{H}_{2} \mathrm{O}_{2}$ in the presence of modified activated carbons. Journal of Hazardous Materials, 162(2-3), 736-742.

https://doi.org/10.1016/j.jhazmat.2008.05.090

Siswoyo, E., Mihara, Y., \& Tanaka, Sh. (2014). Determination of key components and adsorption capacity of a low cost adsorbent based on sludge of drinking water treatment plant to adsorb cadmium ion in water. Applied Clay Science, 97-98, 146-150. https://doi.org/10.1016/j.clay.2014.05.024

Sodaitienè, E., Gefenienė, A., Kaušpèdienè, D., Ragauskas, R., Vaičiūnienè, J., Selskienè, A., Jasulaitienė, V., \& Ramanauskas, R. (2021). Sustainable removal of anodized aluminum dye by groundwater treatment waste: Experimental and modeling. Heliyon, 7(1), e05993.

https://doi.org/10.1016/j.heliyon.2021.e05993

Soni, S., Bajpai, P. K., Bharti, D., Mittal, J., \& Arora, C. (2020). Removal of crystal violet from aqueous solution using iron based metal organic framework. Desalination and Water Treatment Science and Engineering, 205, 386-399. https://doi.org/10.5004/dwt.2020.26387

Sun, Y., Gu, Y., \& Zha, Q. (2021). A novel surface imprinted resin for the selective removal of metal-complexed dyes from aqueous solution in batch experiments: ACB GGN as a representative contaminant. Chemosphere, 280, 130611.

https://doi.org/10.1016/j.chemosphere.2021.130611

Tang, Y., Li, M., Mu, C., Zhou, J., \& Shi, B. (2019). Ultrafast and efficient removal of anionic dyes from wastewater by polyeth- yleneimine-modified silica nanoparticles. Chemosphere, 229, 570-579. https://doi.org/10.1016/j.chemosphere.2019.05.062

Thomas, N., Dionysiou, D. D., \& Pillai, S. C. (2021). Heterogeneous Fenton catalysts: A review of recent advances. Journal of Hazardous Materials, 404(B), 124082. https://doi.org/10.1016/j.jhazmat.2020.124082

Van, H. T., Nguyen, L. H., Hoang, T. K., Tran, T. P., Vo, A. T., Pham, T. T., \& Nguyen, X. C. (2019). Using FeO-constituted iron slag wastes as heterogeneous catalyst for Fenton and ozonation processes to degrade Reactive Red 24 from aqueous solution. Separation and Purification Technology, 224, 431-442. https://doi.org/10.1016/j.seppur.2019.05.048

Wilkins, R. C. (1974). The study of the kinetics and mechanism of reactions of transition metal complexes. Allyn and Bacon.

Wołowiec, M., Pruss, M., Komorowska-Kaufman, A., Lasocka Gomuła, I., Rzepa, G., \& Bajda, T. (2019). The properties of sludge formed as a result of coagulation of backwash water from filters removing iron and manganese from groundwater. SN Applied Sciences, 1, 639.

https://doi.org/10.1007/s42452-019-0653-7

Xiao, C., Jun Li, J., \& Zhang, G. (2018). Synthesis of stable burger-like $\alpha-\mathrm{Fe}_{2} \mathrm{O}_{3}$ catalysts: Formation mechanism and excellent photo-Fenton catalytic performance. Journal of Cleaner Production, 180, 550-559. https://doi.org/10.1016/j.jclepro.2018.01.127

Xu, H.-Y., Prasad, M., \& Liu, Y. (2009). Schorl: a novel catalyst in mineral-catalyzed Fenton-like system for dyeing wastewater discoloration. Journal of Hazardous Materials, 165(1-3), 1186-1192. https://doi.org/10.1016/j.jhazmat.2008.10.108

Xu, W., Xue, W., Huang, H., Wang, J., Zhong, C., \& Mei, D. (2021). Morphology controlled synthesis of $\alpha-\mathrm{Fe}_{2} \mathrm{O}_{3-\mathrm{x}}$ with benzimidazole-modified Fe-MOFs for enhanced photo-Fenton-like catalysis. Applied Catalysis B: Environmental, 291, 120129. https://doi.org/10.1016/j.apcatb.2021.120129

Yao, Y., Wang, L., Sun, L., Zhu, S., Huang, Z., Mao, Y., Lu, W., \& Chen, W. (2013). Efficient removal of dyes using heterogeneous Fenton catalysts based on activated carbon fibers with enhanced activity. Chemical Engineering Science, 101, 424. https://doi.org/10.1016/j.ces.2013.06.009

Zhang, T., Zhao, N., Li, J., Gong, H., An, T., Zhao, F., \& Ma, H. (2017). Thermal behavior of nitrocellulose-based superthermites: Effects of nano- $\mathrm{Fe}_{2} \mathrm{O}_{3}$ with three morphologies. RSC Advances, 7(38), 23583. https://doi.org/10.1039/C6RA28502C

Zheng, X., Jiao, Y., Chai, F., Qu, F., Umar, A., \& Wu, X. (2015). Template-free growth of well-crystalline $\alpha-\mathrm{Fe}_{2} \mathrm{O}_{3}$ nanopeanuts with enhanced visible-light driven photocatalytic properties. Journal of Colloid and Interface Science, 457, 345-352. https://doi.org/10.1016/j.jcis.2015.07.023

Zhu, Y., Zhu, R., Xi, Y., Zhu, J., Zhu, G., \& He, H. (2019). Strategies for enhancing the heterogeneous Fenton catalytic reactivity: A review. Applied Catalysis B: Environmental, 255, 117739. https://doi.org/10.1016/j.apcatb.2019.05.041

Zubrytė, E., Gefenienè, A., Kaušpėdienè, D., Ragauskas, R., Binkienè, R., Selskienė, A., \& Pakštas, V. (2020). Fast removal of $\mathrm{Pb}$ (II) and $\mathrm{Cu}$ (II) from contaminated water by groundwater treatment waste: Impact of sorbent composition. Separation Science and Technology, 55(16), 2855-2868. https://doi.org/10.1080/01496395.2019.1655455 